\title{
13-month climatology of the aerosol hygroscopicity at the free tropospheric site Jungfraujoch (3580 m a.s.l.)
}

\author{
L. Kammermann, M. Gysel, E. Weingartner, and U. Baltensperger \\ Laboratory of Atmospheric Chemistry, Paul Scherrer Institut, 5232 Villigen PSI, Switzerland \\ Received: 5 May 2010 - Published in Atmos. Chem. Phys. Discuss.: 28 May 2010 \\ Revised: 2 November 2010 - Accepted: 4 November 2010 - Published: 16 November 2010
}

\begin{abstract}
A hygroscopicity tandem differential mobility analyzer (HTDMA) was operated at the high-alpine site Jungfraujoch in order to characterize the hygroscopic diameter growth factors of the free tropospheric Aitken and accumulation mode aerosol. More than $\sim 5000 \mathrm{~h}$ of valid data were collected for the dry diameters $D_{0}=35,50,75,110$, 165 , and $265 \mathrm{~nm}$ during the 13 -month measurement period from 1 May 2008 through 31 May 2009. No distinct seasonal variability of the hygroscopic properties was observed. Annual mean hygroscopic diameter growth factors $\left(D / D_{0}\right)$ at $90 \%$ relative humidity were found to be $1.34,1.43$, and 1.46 for $D_{0}=50,110$, and $265 \mathrm{~nm}$, respectively. This size dependence can largely be attributed to the Kelvin effect because corresponding values of the hygroscopicity parameter $\kappa$ are nearly independent of size. The mean hygroscopicity of the Aitken and accumulation mode aerosol at the free tropospheric site Jungfraujoch was found to be $\kappa \approx 0.24$ with little variability throughout the year.

The impact of Saharan dust events, a frequent phenomenon at the Jungfraujoch, on aerosol hygroscopicity was shown to be negligible for $D_{0}<265 \mathrm{~nm}$. Thermally driven injections of planetary boundary layer (PBL) air, particularly observed in the early afternoon of summer days with convective anticyclonic weather conditions, lead to a decrease of aerosol hygroscopicity. However, the effect of PBL influence is not seen in the annual mean hygroscopicity data because the effect is small and those conditions (weather class, season and time of day) with PBL influence are relatively rare.

Aerosol hygroscopicity was found to be virtually independent of synoptic wind direction during advective weather situations, i.e. when horizontal motion of the atmosphere dominates over thermally driven convection. This indicates that the hygroscopic behavior of the aerosol observed at the
\end{abstract}

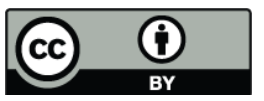

Correspondence to: E. Weingartner (ernest.weingartner@psi.ch)
Jungfraujoch can be considered representative of the lower free troposphere on at least a regional if not continental scale.

\section{Introduction}

Atmospheric aerosol particles can scatter and absorb the incident sunlight, thereby changing the radiation budget of the earth. Hygroscopic water uptake at high relative humidity (RH) influences this mechanism, since larger particles scatter light to a greater extent (Fierz-Schmidhauser et al., 2010b). Additionally, chemical composition and particle diameter influence the ability for particles to take up water and to be activated to cloud condensation nuclei (CCN; McFiggans et al., 2006), which determines their indirect effect on climate, caused through modification of cloud properties (Lohmann and Feichter, 2005). The direct and indirect climate effects of anthropogenic aerosols are complex, associated with nonlinear feedbacks. Therefore they are still among the highest uncertainties in current climate models (IPCC, 2007).

Aerosol hygroscopicity is commonly measured by a hygroscopicity tandem differential mobility analyzer (HTDMA; Liu et al., 1978; Swietlicki et al., 2008). Until recently it was difficult to operate such instruments over longer periods because they require regular maintenance. Efforts were undertaken as part of the EC project EUropean Supersites for Atmospheric Aerosol Research (EUSAAR) to intercompare HTDMA instruments from different research groups, to get them ready for long-term measurements, and to establish quality assurance standards (Duplissy et al., 2009).

Aerosol hygroscopicity was previously measured at numerous sites and in different environments, but only few long-term measurements exist (Swietlicki et al., 2008 and references therein). Short observation periods provide only a snapshot of the aerosol properties and their diurnal cycles for the specific atmospheric transport and weather conditions encountered, but they rarely provide representative information

Published by Copernicus Publications on behalf of the European Geosciences Union. 
on month-to-month variations and seasonality. So far only very few ground-based HTDMA measurements in the free troposphere are available (Swietlicki et al., 2000; Weingartner et al., 2002; Van Dingenen et al., 2005; Sjogren et al., 2008), all of which are short-term observations. Other than that aerosol hygroscopicity in the free troposphere has also been investigated with airborne measurements using optical methods (e.g. Hegg et al., 2007).

In this study we present a 13-month climatology of the aerosol hygroscopicity at the High Alpine Research Station Jungfraujoch (JFJ, $3580 \mathrm{~m}$ a.s.l.). This is, to our knowledge, the first study which investigated the hygroscopicity of the free tropospheric submicron aerosol at subsaturated $\mathrm{RH}$ over the course of a whole year. A detailed analysis of the seasonal cycle, diurnal patterns and synoptic scale weather classes was done in order to characterize the influence from e.g. injections of planetary boundary layer (PBL) air or different source regions on aerosol hygroscopicity.

\section{Experimental}

\subsection{Sampling site}

The Sphinx laboratory of the High Alpine Research Station Jungfraujoch (JFJ) is located at $3580 \mathrm{~m}$ a.s.l. in a mountain saddle on the north crest of the Bernese Alps in Switzerland. Aerosol measurements have been performed for more than 20 years at this site (Baltensperger et al., 1997), since 1995 as part of the Global Atmosphere Watch (GAW) programme (Nyeki et al., 1998; Collaud Coen et al., 2007).

\subsection{Instrumental}

Among other parameters, the total aerosol number concentration, $n_{\text {tot }}$, using a condensation particle counter (CPC, TSI Model 3010, intermittently TSI Model 3722 from 26 June 2008 to 9 February 2009) and the scattering coefficient at the wavelength of $550 \mathrm{~nm}, \sigma_{\mathrm{sp}, 550}$, using an integrating nephelometer (TSI Model 3563) is routinely measured at this site (Collaud Coen et al., 2007). Additionally, the particle number size distribution between $D=17-600 \mathrm{~nm}$ was obtained by a custom built scanning mobility particle sizer (SMPS) and in the diameter range $D=0.3-10 \mu \mathrm{m}$ by an optical particle counter (OPC, Grimm Series 1.108). All instruments were operated in the laboratory at $\sim 25^{\circ} \mathrm{C}$, sampling ambient particles through an inlet system which is constantly heated to $25^{\circ} \mathrm{C}$. Heating the aerosol from ambient temperatures to $25^{\circ} \mathrm{C}$ dries the aerosol and some evaporation of semi-volatile material with high vapor pressures can potentially occur. However, a comparison of parallel indoor and outdoor number size distribution measurements showed that the observed differences in the accumulation mode could mainly be explained by evaporation of water (Nessler et al.,
2003). Furthermore, previous HTDMA measurements at the JFJ performed at $-10^{\circ} \mathrm{C}, 0^{\circ} \mathrm{C}$ and $20^{\circ} \mathrm{C}$ showed no substantial differences (Sjogren et al., 2008); note, these measurements were conducted in different short-term campaigns.

From 1 May 2008 to 31 May 2009 aerosol hygroscopicity measurements were performed using a custom built hygroscopicity tandem differential mobility analyzer (HTMDA) based on the instrument by Weingartner et al. (2002) and Gysel et al. (2002). Prior to the employment at JFJ, the performance of this HTDMA was characterized and intercompared to other HTDMAs in an intercomparison workshop (Duplissy et al., 2009). A detailed scheme of the instrumental setup is given in the paper by Duplissy et al. (2009) where our instrument is termed HTDMA4. The HTDMA works such that the aerosol is dried by a Nafion ${ }^{\mathrm{TM}}$ dryer and then brought to charge equilibrium by means of a ${ }^{85} \mathrm{Kr}$ source. Thereafter, a monodisperse size increment with dry diameter $D_{0}$ is selected using a differential mobility analyzer (DMA) and subsequently humidified by transferring water vapor through a Gore-Tex ${ }^{\mathrm{TM}}$ tube into the sample flow. The size distribution of the humidified aerosol is then obtained by scanning a second DMA coupled to a CPC (TSI Model 3010) across the size range from $0.7 \cdot D_{0}-2.5 \cdot D_{0}$ within $5 \mathrm{~min}$.

The DMAs were operated with a sheath flow rate of $3 \mathrm{~L} / \mathrm{min}$, and a monodisperse sample flow rate of $\sim 0.3 \mathrm{~L} / \mathrm{min}$. The monodisperse sample flow was determined by the CPC sample flow rate $(1.0 \mathrm{~L} / \mathrm{min})$ minus a dilution air flow rate of $\sim 0.7 \mathrm{~L} / \mathrm{min}$, which was added between the second DMA and the CPC. The dilution flow was monitored with a rotameter. The sheath flows were controlled with critical orifices and operated in a closed-loop setup. Differential pressure gauges monitored the flow rates of the instrument. Following the recommendations of the EU-project EUSAAR, DMA1 sequentially selected particles with $D_{0}=35,50,75,110,165$, and $265 \mathrm{~nm}$ (Swietlicki et al., 2008; Duplissy et al., 2009).

RH in DMA1 was permanently $<15 \%$, during the majority of the scans RH in DMA1 was $~ 5 \%$. RH in DMA2 was set to $90 \%$ as recommended by EUSAAR. Precise RH stability was achieved by having both DMAs submersed in a water bath, which was cooled such that $20^{\circ} \mathrm{C} \lesssim T_{\mathrm{DMA}} \lesssim 25^{\circ} \mathrm{C}$. The target RH of DMA2 was measured in the DMA excess air close to DMA2 using a dew point mirror (DewPrime, EdgeTech). The accuracy of the dew point mirror's temperature measurements was $\pm 0.2 \mathrm{~K}$, leading to an accuracy of the $\mathrm{RH}$ measurement at $90 \% \mathrm{RH}$ of $\pm 1.2 \% \mathrm{RH}$. The system was controlled by a custom built software based on LabView 7.1.

Approximately once per month accurate operation of the HTDMA system was verified on site using ammonium sulfate or sodium chloride, thereby checking growth curves and deliquescence RH against theory. With the same frequency, dry GF validation measurements were performed to determine the diameter offset between the two DMAs ( $D_{0}$-offset) and transfer function widths of the HTDMA. The dilution of the sample flow drifted by $\sim 0.2 \mathrm{~L} / \mathrm{min}$ during one month of 
operation, which offset the dry GF measurements by 3\%. The associated increase of the TDMA's kernel function width had no significant effect on the inverted GF-PDFs. Therefore, towards the end of the campaign, dry GF measurements were performed remotely every two weeks while sampling ambient aerosol.

Our custom built HTDMA-setup is well suited for longterm measurements. In addition to minor maintenance work of the custodians, approximately one on-site check per month was needed, however, the setup could still be optimized with e.g. an automated ammonium sulfate nebulizer for remote calibration of the HTDMA. Only a few mechanical parts had to be replaced throughout the full year (pump membranes, smaller pumps for cooling water circulation, and humidification loop) while most parts worked reliably during the whole period (Nafion ${ }^{\mathrm{TM}}$ dryer, RH sensors, CPC).

\subsection{HTDMA data analysis procedures}

Kernel calibration of the HTDMA was done following the procedures given by Gysel et al. (2009), thereby accounting for $D_{0}$-offsets and the true width of the HTDMA transfer function. $D_{0}$-offsets of up to $3 \%$, caused by drifting dilution flow, were linearly interpolated between two validation sessions and accounted for. Data inversion was done using the TDMAinv algorithm by Gysel et al. (2009). The piecewise linear inversion approach was used with the center of the first and last inversion bin at $\mathrm{GF}=0.7$ and $\mathrm{GF}=2.5$, respectively, and a resolution of $\Delta \mathrm{GF}=0.1$. All growth factor probability density functions (GF-PDFs) measured in the range $88 \%<\mathrm{RH}<92 \%$ were recalculated to $\mathrm{RH}=90 \%$ according to Eqs. (3) and (6) by Gysel et al. (2009). All data acquired at lower or higher RH were ignored.

Different integral properties of the inverted GF-PDFs, schematically illustrated in Fig. 1, are calculated and presented in this study. The number weighted mean GF $(\overline{\mathrm{GF}}$, vertical orange line in Fig. 1) is defined as the mean GF of the inverted GF-PDF (see Eq. (C.4) in Gysel et al., 2009). The number fraction of less hygroscopic particles with $\mathrm{GF}<1.25$ $\left(f_{\mathrm{GF}<1.25}\right.$, dark grey shading in Fig. 1$)$ is obtained by integrating the GF-PDF up to GF $=1.25$ (see Eq. (C.8) in Gysel et al., 2009). The mean GF of all more hygroscopic particles with $\mathrm{GF}>1.25\left(\overline{\mathrm{GF}}_{\mathrm{GF}>1.25}\right.$, blue vertical line) is obtained by calculating the mean GF of the subrange of the whole GFPDF at GF $>1.25$ (light grey shading) according to Eq. (C.9) in Gysel et al. (2009).

Hygroscopic growth depends on chemical composition (Raoult effect) and particle size (Kelvin effect; Thomson, 1871). Petters and Kreidenweis (2007) introduced the hygroscopicity parameter $\kappa$, which allows comparing the Raoult term of particles of different dry sizes. Two particles of different size but identical chemical composition will have the same $\kappa$ because the influence of the Kelvin effect is removed

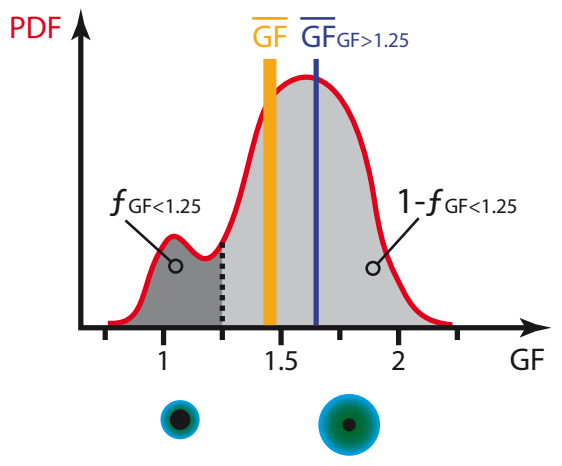

Fig. 1. Schematic growth factor probability density function (GFPDF, red curve) obtained after the inversion of HTDMA data. The total area under the GF-PDF (dark grey plus light gray area) is unity by definition. The mean GF of the GF-PDF, $\overline{G F}$, is indicated by the orange vertical line. The number fraction of the less hygroscopic particles with $\mathrm{GF} \leq 1.25, f_{\mathrm{GF}<1.25}$, is indicated by the dark grey shading, and the mean GF of all more hygroscopic particles (i.e. all those with GF $>1.25$, light grey shading), $\overline{\mathrm{GF}}_{\mathrm{GF}}>1.25$, is indicated by the vertical dark blue line. For illustration, a less hygroscopic particle with an insoluble core and a thin layer of water as well as a more hygroscopic particle with a small insoluble core with a thick layer of aqueous solution are shown at their approximate position below the GF scale.

according to Eq. (2), below. $\kappa$ corresponding to a GF is obtained by

$\kappa=\frac{\left(\mathrm{GF}^{3}-1\right)\left(1-a_{\mathrm{w}}\right)}{a_{\mathrm{w}}}$,

where $a_{\mathrm{w}}$ is the water activity, at which the growth factor was measured. According to Köhler theory (Köhler, 1936), $a_{\mathrm{w}}$ is obtained by dividing the measured RH by the Kelvin correction factor:

$a_{\mathrm{w}}=\frac{\mathrm{RH}}{\exp \left(\frac{4 \sigma_{\mathrm{s}} \nu_{\mathrm{w}}}{R T D}\right)}$,

where $\sigma_{\mathrm{s}}$ is the surface tension of the solution droplet, $v_{\mathrm{w}}$ is the partial molar volume of water in solution, $R$ is the universal gas constant, $T$ is the temperature, and $D$ is the diameter of the droplet. We assumed surface tension of pure water in our calculations. HTDMA-derived $\kappa$ values are only weakly sensitive to the exact value of the surface tension. If the true surface tension was e.g. 10\% lower than that of pure water, then $\kappa$ would be overestimated by only $\sim 1.2 \%$ at $D_{0}=110 \mathrm{~nm}$.

Seasonal variability of aerosol properties was investigated by splitting the whole data set into the following sub-groups: Winter (December 2008, January 2009, February 2009), spring (May 2008, March 2009, April 2009, May 2009), summer (June 2008, July 2008, August 2008), and autumn (September 2008, October 2008, November 2008).

During the warmer season the JFJ is influenced by injections of air parcels from the PBL: air masses from alpine 
valleys and the Swiss plateau are heated up during the day and PBL air parcels from lower altitudes are transported to the site by thermal convection (Nyeki et al., 2000). During such days, pronounced diurnal cycles are measured for various aerosol variables (Lugauer et al., 1998), since the PBL influence disappears during colder parts of the day. During winter this effect is found infrequently, and the air masses present are usually representative of the free tropospheric background conditions (FT). Nyeki et al. (1998) defined the period in the morning hours from 2 a.m. -8 a.m. UTC (=CET$1 \mathrm{~h})$ as FT-conditions. This criterion was also applied in this study to obtain aerosol properties for the FT-conditions only.

\subsection{Alpine weather statistics}

In order to analyze data in the context of the weather situations present, data was further clustered according to the Alpine Weather Statistics (AWS; Schüepp, 1979). The AWS is a synoptic weather classification system, based on the daily analysis of the pressure distribution at the surface and at the 500-hPa level. The classification considers a circular area centered $\sim 80 \mathrm{~km}$ east of JFJ with a radius of $222 \mathrm{~km}$, covering the Swiss Alps and parts of Austria, Italy and France (Wanner et al., 1998). The AWS system consists of three main weather classes (advective, convective, mixed; Table 1), which were originally divided into 40 sub-classes. Among the three main classes, for the advective class the horizontal motion of the atmosphere is predominant, so that in flat terrain the vertical wind components are unimportant. However, the orography of the Alps adds vertical components to this air flow, resulting in well-marked upslope and lee phenomena, such as e.g. Foehn. The convective classes include weather situations where the vertical motion predominantly influences the weather, either as a single effect or in connection with the effects of horizontal motion. For the case where both the horizontal and vertical wind components are significant, an additional type, called the mixed weather class, was added. The Swiss Federal Office of Meteorology and Climatology, MeteoSwiss, classifies each day of the year according to the AWS system. A 50-year analysis of AWS data from 1945-1995 and the history of weather classification systems is given by Wanner et al. (1998), analyses of the latest years of AWS (1995-2008) and the influence on optical properties of aerosol particles measured at JFJ are presented by Collaud Coen et al. (2010).

Here we use a simplified approach, summarizing the 40 sub-classes into 8 main sub-classes, each being characterized by a synoptic motion of the air masses. Note that for some analyses we further combine the four advective sub-classes into a single class, leaving the following five main classes: convective cyclonic (CC), convective indifferent $(\mathrm{CI})$, convective anticyclonic (CA), mixed (M), and advective (Ax). The same classification was chosen in an earlier study (Lugauer et al., 1998). Of special interest is the CA weather class. The clear, sunny weather caused by the large
Table 1. Weather classes according to the Alpine Weather Statistics (AWS): three main classes are defined and thereof eight sub-classes. Sub-classes are characterized by the synoptic scale motion present.

\begin{tabular}{lll}
\hline Main weather class & Sub-class & Synoptic motion \\
\hline Convective & Cyclonic & Lifting \\
& Indifferent & Small scale circulations \\
& Anticyclonic & Subsidence \\
Mixed & - & Active cyclone or jet flow \\
Advective & North & NW-N at $500 \mathrm{hPa}$ \\
& East & NE-SE at $500 \mathrm{hPa}$ \\
& South & S-SW at $500 \mathrm{hPa}$ \\
& West & W at $500 \mathrm{hPa}$ \\
\hline
\end{tabular}

scale subsidence (high pressure conditions) leads in summer to injections of PBL air into the FT, locally driven by thermally induced vertical transport over mountain slopes and thus to distinct diurnal patterns with higher aerosol concentrations during the afternoon.

\section{Results}

\subsection{Annual cycle of hygroscopic properties}

Between 10100 and 10600 valid GF-PDFs were obtained for each dry size during the 13 months of measurement on the JFJ.

Seasonal mean GF-PDFs were calculated by averaging these individual GF-PDFs for each season and dry size (Fig. 2a-f). It has to be emphasized that mean GF-PDFs represent the mean distribution of growth factors, where the appearance of e.g. a broad mode or two distinct modes in the mean GF-PDF does not imply that particles of distinctly different hygroscopicity and thus composition were simultaneously observed. Mean GF-PDFs of particles with $D_{0}=35 \mathrm{~nm}$ and $D_{0}=50 \mathrm{~nm}$ were found to be very similar (Fig. 2a and b), characterized by a broad peak within the range of $1.10 \lesssim \mathrm{GF} \lesssim 1.60$, indicating that the full range of compositions from particles dominated by organics and/or black carbon to particles dominated by inorganic salts are present in the Aitken mode.

In relation to their mass small particles efficiently acquire hygroscopic material through condensation. Absence of a distinct non-hygroscopic mode shows that nearest emissions of small non-hygroscopic particles in the diameter range between $D_{0}=35 \mathrm{~nm}$ and $D_{0}=50 \mathrm{~nm}$ occur too far away to retain their original properties until arrival at the JFJ. Differences between seasonal mean GF-PDFs are minor and can be due to many different reasons, as will be shown later. For example the mean GF-PDFs at $D_{0}=50 \mathrm{~nm}$ observed in autumn and summer might seem clearly different at the first glance, but they actually have $84 \%$ of their area in common, while 

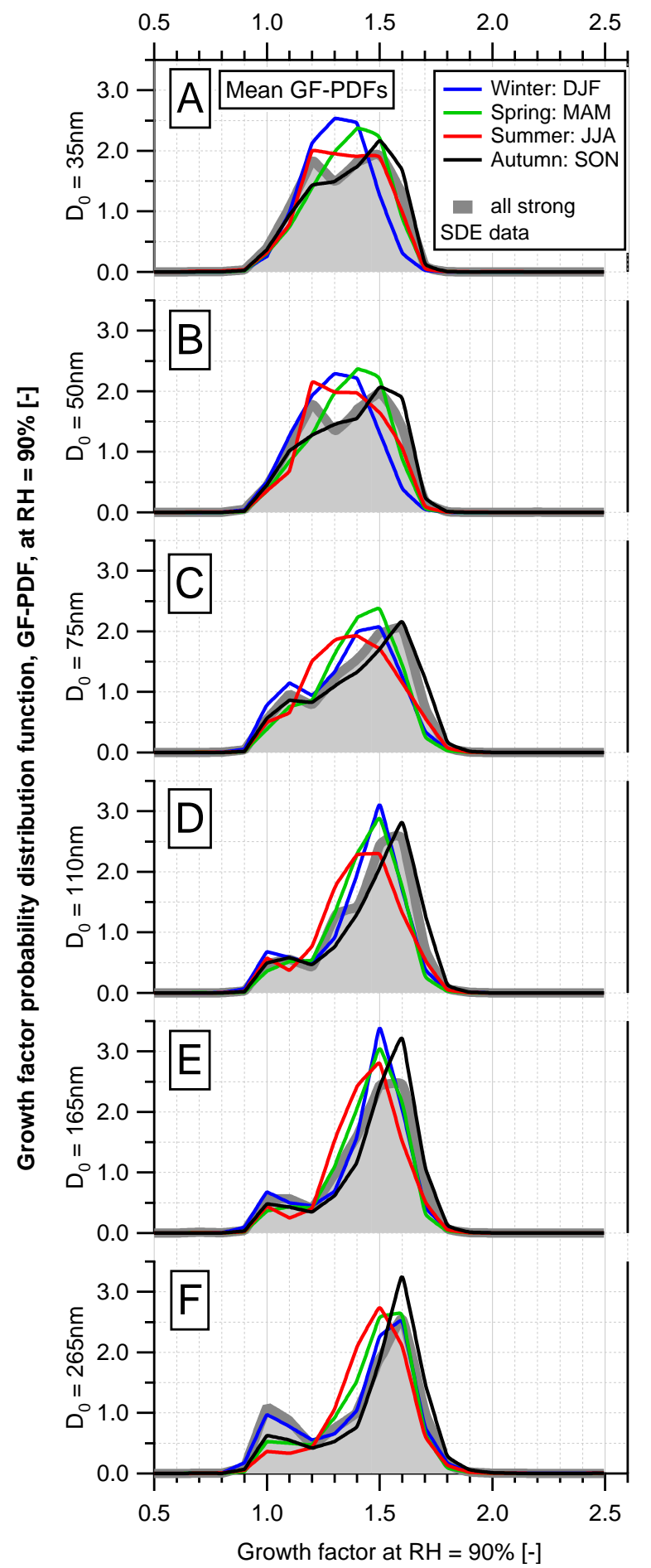

Fig. 2. Mean GF-PDFs for different dry sizes split by season as well as for strong SDE data from all seasons.

only $16 \%$ of the particles are differently distributed with respect to GF.

The mean GF-PDFs of all sizes with $D_{0} \geq 75 \mathrm{~nm}$ are similar in shape throughout all seasons. They are characterized

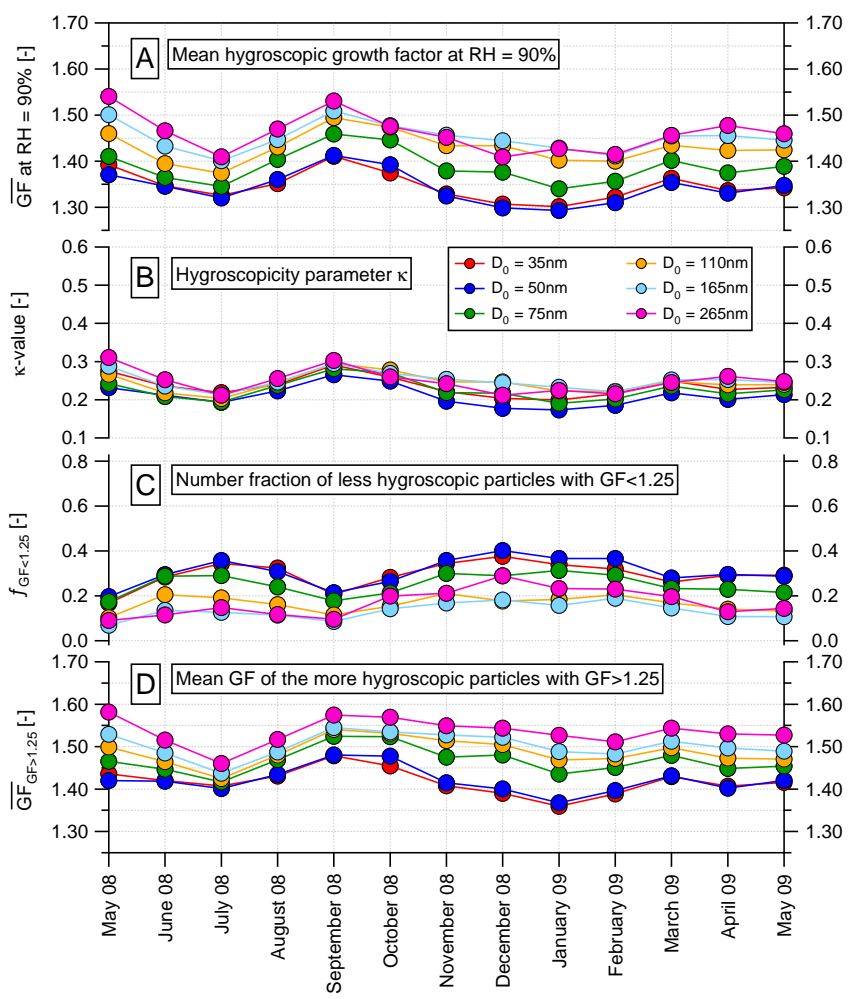

Fig. 3. Annual cycles (A) of the mean hygroscopic growth factor $(\overline{\mathrm{GF}})$ at $90 \% \mathrm{RH},(\mathbf{B})$ of the corresponding hygroscopicity parameter $\kappa,(\mathbf{C})$ of the number fraction of less hygroscopic particles with $\mathrm{GF}<1.25, f_{\mathrm{GF}<1.25}$, and (D) of the mean GF of the more hygroscopic particles with $\mathrm{GF}>1.25, \overline{\mathrm{GF}}_{\mathrm{GF}}>1.25$.

by a dominant contribution of more hygroscopic particles with growth factors between $\sim 1.25-1.7$, as well as a minor contribution of less hygroscopic particles with growth factors $\lesssim 1.25$. Differences between different seasons are minor and can be attributed to unknown variability for the most part. However, in summer the more hygroscopic mode is shifted to slightly smaller growth factors and the number fraction of particles with $\mathrm{GF}<1.25$ tends to be slightly smaller.

Presumably, this small difference observed in summer is due to secondary organic aerosol (SOA) formation. More SOA material produced through photochemical activity is available to condense on particles during the summer months, when concentrations of SOA precursor gases are generally higher.

The mean GF ( $\overline{\mathrm{GF}}$, see Sect. 2.3) was determined for each individual GF-PDF and monthly averages of $\overline{\mathrm{GF}}$ were calculated for every dry size (Fig. 3a). Monthly mean values of $\overline{\mathrm{GF}}$ ranged between 1.29 and 1.54, and were larger for larger $D_{0}$ than for smaller $D_{0}$ during most of the months.

The size dependence of $\overline{\mathrm{GF}}$ is mainly caused by the Kelvin effect, as will be shown later. An earlier publication by Sjogren et al. (2008), reporting HTDMA measurements from short-term experiments during the summer and winter 
season, found $\overline{\mathrm{GF}}$ to be lower in summer compared to winter, whereas no pronounced seasonal trend was found for $\overline{\mathrm{GF}}$ in this study. Slightly lower $\overline{\mathrm{GF}}$ were measured in summer months (June 2008-August 2008), while $\overline{\mathrm{GF}}$ was somewhat higher than average in May 2008 and September 2008. The decrease of $\overline{\mathrm{GF}}$ in the summer months and the increase of $\overline{\mathrm{GF}}$ in May 2008 and September 2008 are probably within the natural month-to-month variations: This is also confirmed by the fact that the difference of $\overline{\mathrm{GF}}$ between May 2008 and May 2009 is similar in magnitude to the observed seasonal variability of $\overline{\mathrm{GF}}$.

Monthly mean $\kappa$ values, determined from the observed hygroscopic growth according to Eqs. (1) and (2), varied in the range between 0.17 and 0.31 and were similar for all $D_{0}$ (Fig. $3 \mathrm{~b}$ ). The fact that the $\kappa$ values are nearly independent of size throughout all seasons shows that the observed size dependence of $\overline{\mathrm{GF}}$ can largely be explained by the Kelvin effect. We therefore conclude that the annual mean $\kappa$ value of $\kappa=0.24$ (see Table 2) is a good approximation in any model that needs a simple description for the hygroscopicity of the Aitken and accumulation mode aerosol at the free tropospheric site JFJ. Jurányi et al. (2010a,b) found that for a reliable CCN prediction the temporal variability of the chemical composition can be neglected at the JFJ whereas it is important to know the mean chemical composition. The monthly and annual mean values of $\kappa$ observed at the JFJ mostly fall within the range $\kappa=0.3 \pm 0.1$, which is the hygroscopicity value recommended for continental sites in a recent publication (Andreae and Rosenfeld, 2008).

A detailed analysis of the short-term variability of $\overline{\mathrm{GF}}$ is provided in Appendix A and Fig. A1. Aerosol hygroscopicity was only moderately variable. $50 \%$ of individual $\overline{\mathrm{GF}}$ measurements fall within a narrow band of $\Delta \mathrm{GF} \approx 0.15$ around the median value. Nevertheless, short-term variability, seasonality, size dependence of aerosol hygroscopicity and aerosol mixing state as provided in Figs. 2-4 and Fig. A1 as well as Table 2 should be considered in models describing processes that are sensitive to small variations of aerosol hygroscopicity.

$\overline{\mathrm{GF}}$ at a certain dry size can vary in time because either the particles become generally more hygroscopic or because the relative amounts of more and less hygroscopic particles vary, or a combination of both. The relative importance of these two effects was further investigated by calculating the number fraction of less hygroscopic particles with a $\mathrm{GF}<1.25$ $\left(f_{\mathrm{GF}<1.25}\right)$ and the mean $\mathrm{GF}$ of all more hygroscopic particles with a GF $>1.25\left(\overline{\mathrm{GF}}_{\mathrm{GF}>1.25}\right)$ as described in Sect. 2.3 and illustrated in Fig. 1. The number fraction of more hygroscopic particles with $\mathrm{GF}>1.25$ is by definition equal to $1-f_{\mathrm{GF}<1.25}$. This particular cut at $\mathrm{GF}=1.25$ between the less and more hygroscopic particles was chosen because the averaged GF-PDFs at $\mathrm{RH}=90 \%$ typically have a minimum at $\mathrm{GF} \approx 1.25$ (Fig. 2), though the separation between less and more hygroscopic particles disappears at the smallest dry sizes. Changing the selected cut-off between GF $=1.20$ and
$\mathrm{GF}=1.30$ had no qualitative and only a small quantitative effect on the above integral parameters.

$f_{\mathrm{GF}<1.25}$ gives an idea about the influence of less hygroscopic compounds on $\overline{\mathrm{GF}}$. Less hygroscopic compounds possibly contributing to $f_{\mathrm{GF}<1.25}$ at the $\mathrm{JFJ}$ are organics, soot or dust. Monthly mean values of $f_{\mathrm{GF}<1.25}$ range between 0.07 and 0.40 . The more hygroscopic mode is clearly limited to GF $>1.25$ at dry sizes $D_{0} \geq 75 \mathrm{~nm}$, whereas at dry sizes $D_{0} \leq 50 \mathrm{~nm}$ the leading tail of the single broad mode extends to $\mathrm{GF}<1.25$ (Fig. 2). This explains why $f_{\mathrm{GF}<1.25}$ is consistently larger for the smallest measured dry sizes compared to the larger measured dry sizes (Table 2).

Monthly mean $\overline{\mathrm{GF}}_{\mathrm{GF}}>1.25$ varied between 1.36 and 1.58 for the various $D_{0}$ throughout the year, with systematically larger values at larger measured dry diameters (Table 2). Both $f_{\mathrm{GF}<1.25}$ and $\overline{\mathrm{GF}}_{\mathrm{GF}>1.25}$ showed little seasonal variability though a small trend of slightly smaller $f_{\mathrm{GF}<1.25}$ and $\overline{\mathrm{GF}}$ during summer was observed (Fig. $3 \mathrm{~b}$ and $3 \mathrm{c}$ ), as previously mentioned. Smaller $f_{\mathrm{GF}<1.25}$ and smaller $\overline{\mathrm{GF}}_{\mathrm{GF}>1.25}$ have a compensating effect on $\overline{\mathrm{GF}}$, thereby explaining why $\overline{\mathrm{GF}}$ was not significantly different during summer (Fig. 3a).

In a further analysis separate mean GF-PDFs were determined for the following subsets of the whole data set: free tropospheric (FT) conditions excluding Saharan dust events (SDE), strong SDE, as well as for the four seasons winter, spring, summer and autumn. The results of this analysis along with the overall mean GF-PDF are shown in Fig. 4 as box plots of GF-percentiles for the dry diameters 50, 110 and $265 \mathrm{~nm}$. GF-percentiles are equivalent to a simplified GF-PDF because each GF-percentile corresponds to a single point of the cumulative distribution function. One advantage of using GF-percentiles is that this makes the results obtained by different inversion approaches directly comparable.

The GF-percentiles as well as the mean GF observed during the FT conditions are almost equal to those of the overall annual mean for all dry sizes (Fig. 4 and Table 2). However, a detailed analysis of diurnal cycles and weather classes presented below in Sect. 3.4 shows why PBL influence has no effect on the annual mean hygroscopicity of the aerosol, even though growth factors are significantly lowered during periods with PBL influence.

The box plots of the four seasons (Fig. 4 and Table 2) confirm that there is no distinct seasonal variability in the GF at JFJ. The aerosol was most hygroscopic during autumn, which is mainly caused by the high values observed in September (Fig. 3) and most likely within natural variability. The other notable difference is that at $D_{0}=265 \mathrm{~nm}$ the particles' 10th and 25th percentile GF were lower in winter compared to the other seasons, while the 50th, 75th and 90th percentile GF were similar. This means that very small GFs were more frequently observed, whereas the upper half of the GF-PDF remained unchanged. More frequent influence from Saharan dust is a possible reason for the appearance of those particles with $\mathrm{GF}<1.2$, though dust from construction works (rock drilling works conducted around the station during this 
Table 2. Mean values for dry diameters $\left(D_{0}\right)$ of $50,110,265 \mathrm{~nm}$ of the mean hygroscopic growth factor $(\overline{\mathrm{GF}})$ at $90 \%$ RH, of the hygroscopicity parameter $\kappa$, of the number fraction of the GF-PDF $<1.25\left(f_{\mathrm{GF}<1.25}\right)$, of the GF of all more hygroscopic particles with GF $>1.25$ $\left(\overline{\mathrm{GF}}_{\mathrm{GF}}>1.25\right)$, and 10th, 25th, 50th, 75th, and 90th GF percentile of the mean GF-PDF. Data are reported for the complete 13-month data set, for strong Saharan dust events, for free troposphere conditions ( 2 a.m. -8 a.m. UTC $=$ CET- $1 \mathrm{~h}$ ), and for the seasons winter, spring, summer, and autumn.

\begin{tabular}{|c|c|c|c|c|c|c|c|c|c|c|}
\hline \multirow{4}{*}{$\begin{array}{l}\text { Annual mean } \\
\text { (all months) }\end{array}$} & \multirow{2}{*}{$\frac{D_{0}}{50 \mathrm{~nm}}$} & \multirow{2}{*}{$\frac{\overline{\mathrm{GF}}^{*}}{1.34}$} & \multirow{2}{*}{$\frac{\kappa}{0.21}$} & \multirow{2}{*}{$\frac{f_{\mathrm{GF}<1.25}^{*}}{0.31}$} & \multirow{2}{*}{$\frac{\overline{\mathrm{GF}}_{\mathrm{GF}>1.25}^{*}}{1.42}$} & \multicolumn{5}{|c|}{ percentiles of the GF-PDF* } \\
\hline & & & & & & 1.11 & 1.22 & 1.35 & 1.47 & 1.57 \\
\hline & $110 \mathrm{~nm}$ & 1.43 & 0.24 & 0.17 & 1.49 & 1.13 & 1.33 & 1.46 & 1.56 & 1.64 \\
\hline & $265 \mathrm{~nm}$ & 1.46 & 0.25 & 0.17 & 1.53 & 1.1 & 1.35 & 1.51 & 1.6 & 1.68 \\
\hline \multirow{3}{*}{$\begin{array}{l}\text { Free troposphere conditions } \\
\text { (no Saharan dust events) }\end{array}$} & $50 \mathrm{~nm}$ & 1.36 & 0.22 & 0.27 & 1.43 & 1.12 & 1.24 & 1.37 & 1.49 & 1.58 \\
\hline & $110 \mathrm{~nm}$ & 1.45 & 0.26 & 0.15 & 1.5 & 1.14 & 1.35 & 1.48 & 1.58 & 1.66 \\
\hline & $265 \mathrm{~nm}$ & 1.47 & 0.26 & 0.16 & 1.54 & 1.12 & 1.37 & 1.52 & 1.61 & 1.69 \\
\hline \multirow{3}{*}{$\begin{array}{l}\text { Only strong Saharan dust events } \\
\text { (all months) }\end{array}$} & $50 \mathrm{~nm}$ & 1.35 & 0.22 & 0.33 & 1.44 & 1.09 & 1.19 & 1.36 & 1.51 & 1.59 \\
\hline & $110 \mathrm{~nm}$ & 1.44 & 0.25 & 0.16 & 1.5 & 1.11 & 1.32 & 1.48 & 1.58 & 1.65 \\
\hline & $265 \mathrm{~nm}$ & 1.42 & 0.22 & 0.26 & 1.53 & 1.02 & 1.2 & 1.48 & 1.6 & 1.67 \\
\hline Winter & $50 \mathrm{~nm}$ & 1.3 & 0.18 & 0.38 & 1.39 & 1.08 & 1.18 & 1.31 & 1.42 & 1.51 \\
\hline \multirow[t]{2}{*}{ (Dec, Jan, Feb) } & $110 \mathrm{~nm}$ & 1.41 & 0.23 & 0.19 & 1.48 & 1.08 & 1.32 & 1.45 & 1.54 & 1.62 \\
\hline & $265 \mathrm{~nm}$ & 1.42 & 0.22 & 0.25 & 1.53 & 1.03 & 1.24 & 1.48 & 1.59 & 1.66 \\
\hline Spring & $50 \mathrm{~nm}$ & 1.35 & 0.22 & 0.26 & 1.42 & 1.12 & 1.24 & 1.37 & 1.48 & 1.56 \\
\hline \multirow{2}{*}{ (Mar, Apr, May) } & $110 \mathrm{~nm}$ & 1.44 & 0.25 & 0.14 & 1.48 & 1.15 & 1.32 & 1.44 & 1.54 & 1.61 \\
\hline & $265 \mathrm{~nm}$ & 1.48 & 0.27 & 0.14 & 1.55 & 1.12 & 1.33 & 1.48 & 1.58 & 1.65 \\
\hline Summer & $50 \mathrm{~nm}$ & 1.34 & 0.21 & 0.32 & 1.42 & 1.13 & 1.22 & 1.34 & 1.47 & 1.57 \\
\hline \multirow{2}{*}{ (Jun, Jul, Aug) } & $110 \mathrm{~nm}$ & 1.4 & 0.22 & 0.19 & 1.46 & 1.15 & 1.29 & 1.42 & 1.53 & 1.62 \\
\hline & $265 \mathrm{~nm}$ & 1.45 & 0.24 & 0.13 & 1.5 & 1.21 & 1.36 & 1.47 & 1.57 & 1.65 \\
\hline & $50 \mathrm{~nm}$ & 1.38 & 0.24 & 0.28 & 1.46 & 1.1 & 1.23 & 1.4 & 1.53 & 1.61 \\
\hline \multirow[t]{2}{*}{ (Sep, Oct, Nov) } & $110 \mathrm{~nm}$ & 1.47 & 0.27 & 0.16 & 1.53 & 1.13 & 1.36 & 1.52 & 1.61 & 1.68 \\
\hline & $265 \mathrm{~nm}$ & 1.49 & 0.27 & 0.17 & 1.56 & 1.1 & 1.39 & 1.55 & 1.63 & 1.71 \\
\hline
\end{tabular}

$*$ at $\mathrm{RH}=90 \%$.

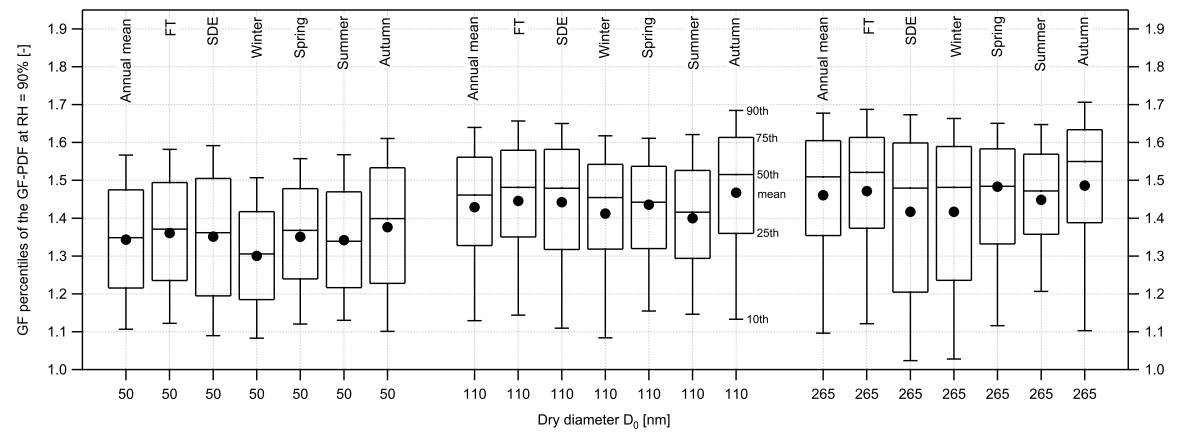

Fig. 4. 10th, 25th, 50th, 75th, and 90th percentile of the GF-PDF for $D_{0}=50,110$, and $265 \mathrm{~nm}$ for the complete 13-month data set, for strong Saharan dust events, for free troposphere conditions ( 2 a.m. -8 a.m. UTC=CET- $1 \mathrm{~h}$ ) and as well as for the seasons winter, spring, summer, and autumn.

particular winter) and wind erosion of local rock material may have had an influence on our measurements too.

\subsection{Aerosol hygroscopicity during Saharan dust events}

Saharan dust events increase the total mass and change the integral optical properties of the aerosol at the JFJ significantly (Cozic et al., 2008; Collaud Coen et al., 2004). Both mass and optical properties are dominated by the large accumulation mode and coarse mode particles. Collaud Coen et al. (2004) have shown that SDEs at the JFJ can be detected via the wavelength dependence of the single scattering albedo. Unfortunately the aerosol parameters required for this SDE criterion were not available for the whole 13month period. Since SDE periods are also characterized by an enhanced fraction of large particles, we defined strong 
SDE periods as

$$
\frac{n_{D>1 \mu \mathrm{m}}}{\left(n_{\mathrm{SMPS}}+n_{D>1 \mu \mathrm{m}}\right)} \geq 6 \times 10^{-4}
$$

where $n_{D>1 \mu \mathrm{m}}$ is the number concentration of particles with optical diameter $D>1 \mu \mathrm{m}$ as measured by the OPC, and $n_{\text {SMPS }}$ is the integrated number concentration of particles with mobility diameter in the range $D=17-600 \mathrm{~nm}$ as measured by the SMPS. The validity of this criterion was crosschecked against the criterion by Collaud Coen et al. (2004) for all times, when all necessary aerosol parameters were available (see Appendix B).

HTDMA data allow us to investigate whether SDE particles are also present at diameters $D_{0} \leq 265 \mathrm{~nm}$. This was investigated previously using data from shorter campaigns at JFJ and it was found that a substantial fraction of the $D_{0}=250 \mathrm{~nm}$ particles can be non-hygroscopic dust during extreme SDEs (Sjogren et al., 2008), while no SDE effect was seen at $D_{0} \leq 100 \mathrm{~nm}$. The 13 -month data set of this study (see Table 2, Figs. 2 and 4) shows now that typical strong SDE events have no influence on the aerosol hygroscopicity at diameters up to $D_{0}=165 \mathrm{~nm}$. Even at $D_{0}=265 \mathrm{~nm}$ only very little influence of SDE was observed: the mean GF during all strong SDE was slightly smaller compared to the overall annual mean value because the number fraction of particles with $\mathrm{GF}<1.2$ increased slightly, while the dominant mode of more hygroscopic particles remained unchanged (Table 2, Figs. 2f and 4). Therefore the distinct SDE effect at $D_{0}=250 \mathrm{~nm}$ reported by Sjogren et al. (2008) can be considered to be a rare and extreme event.

The results of this study show that dust particles during SDEs have no significant influence on the total particle number concentration, because the number fraction of aerosol particles with $D_{0}>265 \mathrm{~nm}$ is negligible at the JFJ, even during SDE, and the number fraction of dust particles becomes vanishingly small at $D_{0}<265 \mathrm{~nm}$. As a consequence dust particles are not relevant for the total number of $\mathrm{CCN}$ at this site (after a transport distance of several thousand kilometers) and with that they are unlikely to have an indirect climate effect through the formation of cloud droplets. This has been confirmed by CCN measurements at the JFJ site (Jurányi et al., 2010a). However, they may still influence mixed-phase and ice clouds, if they were to act as ice nuclei.

Fierz-Schmidhauser et al. (2010a) have shown that the aerosol optical properties are strongly influenced by SDE at the JFJ. In contrast to the HTDMA observations, the light scattering enhancement factor $f(\mathrm{RH})$ at elevated $\mathrm{RH}-$ an integral optical property of the aerosol - dropped considerably during a SDE. The observation that SDEs influence $\sigma_{\mathrm{sp}}$ and $f(\mathrm{RH})$ without increasing $n_{\text {tot }}$ nor decreasing GF at $D_{0}<265 \mathrm{~nm}$ at the same time can be explained by the fact that although the dust particles are not very numerous, they are non-hygroscopic and predominantly in the coarse mode size range (see Fig. B1). Because they are larger they have a more dominant effect on scattering cross section relative to the FT or PBL accumulation mode. This shows, in agreement with the results by Collaud Coen et al. (2004), that Saharan dust particles at the JFJ can alter the integral optical properties of the aerosol and their RH-dependence significantly, and with that they can have an influence on the direct aerosol effect.

\subsection{Diurnal cycles of the aerosol hygroscopicity}

Most of the time the JFJ is in the lower free troposphere, though influence from injections of PBL air can sometimes be observed as distinct diurnal variations in the extensive aerosol parameters, particularly during convective summer days. Here we investigate the diurnal patterns of the hygroscopic growth factors for routinely determined weather classes at JFJ along with the total aerosol number concentration, $n_{\text {tot }}$, and the scattering coefficient at $\lambda=550 \mathrm{~nm}, \sigma_{\mathrm{sp}, 550}$, in order to see whether PBL injections or other processes have a significant influence on aerosol hygroscopicity.

PBL influence at the JFJ is known to increase both $n_{\text {tot }}$ and $\sigma_{\mathrm{sp}, 550}$ (Weingartner et al., 1999; Nyeki et al., 1998). By contrast, new particle formation events in the FT mainly increase $n_{\text {tot }}$ due to high concentrations of nucleation mode particles (Weingartner et al., 1999), whereas $\sigma_{\mathrm{sp}, 550}$ hardly increases. Thus, $n_{\mathrm{tot}}$ and $\sigma_{\mathrm{sp}, 550}$ are used here to distinguish between influence from PBL injections or new particle formation events.

A distinct diurnal pattern in $\sigma_{\mathrm{sp}, 550}$ (Fig. 5h) and $n_{\text {tot }}$ (Fig. 5a) with an amplitude of more than factor of 2 and maxima in the afternoon was observed during summer for the convective anticyclonic weather class, due to influence from thermally driven PBL injections during daytime. $\overline{\mathrm{GF}}$ exhibited a concurrent diurnal pattern though with opposite sign, i.e. a minimum in the early afternoon. The maximum of $\overline{\mathrm{GF}}$ occurs in the early morning and is higher than the maximum $\overline{\mathrm{GF}}$ during any other weather class. The diurnal pattern of $\overline{\mathrm{GF}}$ spans $\kappa$ values from ca. 0.33 to ca. 0.15 and ca. 0.27 to ca. 0.20 at $D_{0}=35 \mathrm{~nm}$ and $265 \mathrm{~nm}$, respectively, such that the diurnal mean $\kappa$ value remains similar to the other weather classes. The decrease of $\overline{\mathrm{GF}}$ in the afternoon indicates that the aerosol from PBL injections is typically somewhat less hygroscopic, which can be explained by a relatively larger fraction of less hygroscopic compounds such as organic matter compared to more hygroscopic inorganic salts (Cozic et al., 2008). The diurnal pattern of $\overline{\mathrm{GF}}$ is mainly caused by a decrease of the GF of the main more hygroscopic mode $\left(\overline{\mathrm{GF}}_{\mathrm{GF}>1.25}\right.$; Appendix Fig. C1). The number fraction of less hygroscopic particles $\left(f_{\mathrm{GF}<1.25}\right.$; Appendix Fig. C2) exhibits little diurnal variation at diameters larger than $110 \mathrm{~nm}$. The afternoon maximum of $f_{\mathrm{GF}<1.25}$ at diameters smaller than $110 \mathrm{~nm}$ can be attributed to a shift of the main broad growth mode (Fig. 2) to smaller GFs, such that part of it falls below $\mathrm{GF}=1.25$. Less pronounced diurnal patterns were also observed during spring and autumn for the 
convective anticyclonic class, whereas no clear diurnal pattern is observed during winter.

In summary, the convective anticyclonic weather class is clearly influenced by PBL injections during the warmer months, which results in the highest absolute values and the strongest seasonal variation of the $\sigma_{\mathrm{sp}, 550}$ and $n_{\text {tot }}$, as well as in the strongest diurnal amplitudes of $\sigma_{\mathrm{sp}, 550}, n_{\mathrm{tot}}$, and $\overline{\mathrm{GF}}$ out of all weather classes. Similar diurnal patterns though clearly less pronounced were also observed for the cyclonic indifferent weather class during the warmer season. These findings agree with the more detailed study of the extensive aerosol properties at the JFJ by Collaud Coen et al. (2010).

For the convective cyclonic, mixed and advective weather classes neither $\sigma_{\mathrm{sp}, 550}$ (Fig. 5h) nor $\overline{\mathrm{GF}}$ (Fig. 5b-g) exhibited a distinct diurnal pattern and the absolute values of the extensive aerosol properties are clearly lower than for the convective anticyclonic weather class. This reveals that PBL influence is only minor or completely absent for these three weather classes throughout the whole year, in accordance with the results by Collaud Coen et al. (2010). On the other hand $n_{\text {tot }}$ often shows a maximum in the afternoon, which can partially be attributed to new particle formation events. Condensation of less hygroscopic secondary organic matter on existing Aitken and accumulation mode particles during new particle formation events could in principle decrease $\overline{\mathrm{GF}}$. However, this effect was not clearly observed, except possibly for the smaller dry diameters during advective weather situations.

The above analysis revealed that the influence from PBL injections typically decreases aerosol hygroscopicity. However, the fact that the annual mean GF-PDFs of the whole data set, and of the free tropospheric conditions only are very similar shows that the PBL influence has essentially no effect on the annual mean hygroscopic properties. This can be explained by two reasons: First, the effect of PBL influence on the hygroscopicity is relatively small, i.e. the maxima and minima of $\overline{\mathrm{GF}}$ are $\sim 1.5$ and $\sim 1.3$, respectively, for those weather situations with the strongest diurnal amplitude. Second, those conditions (weather class, season, and time of day) with lowered aerosol hygroscopicity due to PBL influence cover only a minor fraction of the whole year. By contrast, the PBL influence causes a distinct seasonal pattern of the extensive aerosol properties $\sigma_{\mathrm{sp}, 550}$ and $n_{\text {tot }}$, because the maxima and minima of these quantities differ by more than a factor of 2 (see Fig. 5a and h), for those weather situations with the strongest diurnal amplitude.

\subsection{Influence of synoptic scale wind direction}

The above analyses showed that the aerosol properties measured at the JFJ are representative of the lower free troposphere most of the time, even though PBL influence is clearly seen for certain weather classes. The analysis of this section aims at addressing the question whether the aerosol hygroscopicity observed at the JFJ is just locally representative for the lower free troposphere or on a larger scale. For this purpose we split all data from the advective AWS classes (including more than one third of total measurement time) by the synoptic scale wind direction (north, east, south and west, as described in Table 1). The advective classes were chosen because horizontal motion of the atmosphere dominates over thermally driven convection under these conditions, which is reflected in the absence of a distinct diurnal pattern in $\sigma_{\mathrm{sp}, 550}$ (Fig. 5h) and in $\overline{\mathrm{GF}}$ (Fig. 5b-g).

Statistics of the aerosol parameters $\overline{\mathrm{GF}}, f_{\mathrm{GF}<1.25}$, $\overline{\mathrm{GF}}_{\mathrm{GF}>1.25}, n_{\mathrm{tot}}$ and $\sigma_{\mathrm{sp}, 550}$ separated by wind direction are shown as box plots in Fig. 6a-e. The size dependence of $\overline{\mathrm{GF}}$ for the various advective weather classes showed the same trend as previously presented (Figs. 2 and 4, and Table 2) and discussed (Sect. 3.1). The integral hygroscopicity parameters $\overline{\mathrm{GF}}$ (Fig. 6a), $f_{\mathrm{GF}<1.25}$ (Fig. 6b), and $\overline{\mathrm{GF}}_{\mathrm{GF}>1.25}$ (Fig. 6c) are very similar for all four synoptic wind directions at any dry size. The small differences in the mean $\overline{\mathrm{GF}}$ for different wind directions correspond to a difference of as little as $\Delta \kappa= \pm 0.02$ compared to the overall mean $\kappa$ value at the corresponding dry size. This indicates that the hygroscopic properties observed at the JFJ can be considered to be representative of the lower free troposphere on at least a regional if not continental scale.

Nevertheless, there are subtle differences between the different wind directions. The mean value as well as the 75th and 90th percentiles of $\sigma_{\mathrm{sp}, 550}$ were highest for the southern advective subclass (Fig. 6e). The other feature for southern advection is that the 10th and 25th percentiles of $\overline{\mathrm{GF}}$ at $D_{0}=265 \mathrm{~nm}$ are clearly lower than for the other wind directions (Fig. 6a). These lowered $\overline{\mathrm{GF}}$ are caused by an increased fraction of less hygroscopic particles (cf. 90th and 75th percentiles of $f_{\mathrm{GF}<1.25}$ in Fig. $6 \mathrm{~b}$ ), whereas the mean GF of the more hygroscopic mode remains unchanged (cf. $\overline{\mathrm{GF}}_{\mathrm{GF}}>1.25$ in Fig. 6c).

A more detailed analysis revealed that these outstanding high $\sigma_{\mathrm{sp}, 550}$ and high $f_{\mathrm{GF}<1.25}$ values during the southern advective weather classes have different causes because they did not occur simultaneously. The high $\sigma_{\mathrm{sp}, 550}$ values, reflecting high aerosol loadings, can likely be attributed to sources in the polluted Po valley south of the Alps. The hygroscopic growth factors observed during these episodes were similar to the other weather conditions. SDEs can be ruled out as a cause for the high $f_{\mathrm{GF}<1.25}$ at $D_{0}=265 \mathrm{~nm}$, as occasionally observed during the southern advective weather classes. The influence of SDE on hygroscopic growth factor distributions has generally been shown to be small (Sect. 3.2) and excluding all SDEs from the analysis presented in Fig. 6 did not change the results. The high $f_{\mathrm{GF}<1.25}$ at $D_{0}=265 \mathrm{~nm}$ typically occurred during periods with very low aerosol loadings, thereby bringing a different hypothesis into play. The most precipitation on the southern upslope side of the Alps occurs during the southern advective weather classes (Lugauer et al., 1998). The occurrence of high $f_{\mathrm{GF}<1.25}$ at 


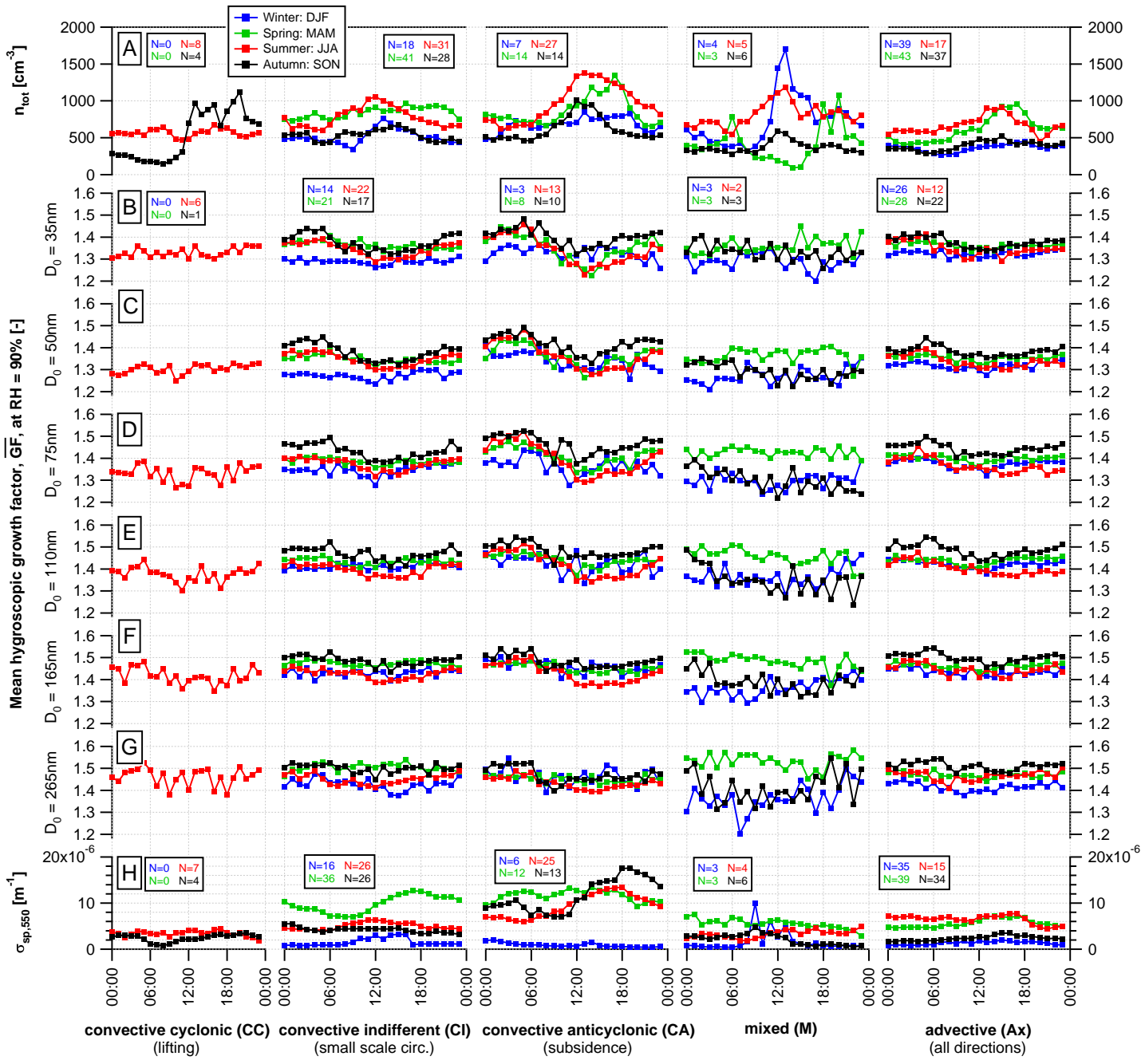

Fig. 5. Diurnal cycles (A) of the median of the total number concentration, (B-G) of the mean hygroscopic growth factor $(\overline{\mathrm{GF}})$ at $90 \%$ RH for $D_{0}=35,50,75,110,165,265 \mathrm{~nm}$, and $(\mathbf{H})$ of the scattering coefficient at the wavelength $\lambda=550 \mathrm{~nm}$ (green light). Data was split by the daily weather classes from the Alpine Weather Statistics and by season.

$D_{0}=265 \mathrm{~nm}$ could be caused by cloud formation and precipitation leading to activation and removal of most particles with $D_{0}=265 \mathrm{~nm}$, except for the least hygroscopic ones. This effect would be less important at the smaller particle diameters shown in Fig. 6, where the number fraction of $\mathrm{CCN}$ active particles decreases rapidly (Henning et al., 2002). Besides the above hypothesis, the influence from the rock drilling works, conducted around the station during winter 2008/2009, cannot be fully excluded as a source of additional non-hygroscopic particles at $D_{0}=265 \mathrm{~nm}$ specific to southern advective weather classes.

The northern and eastern advective subclasses are characterized by highest $n_{\text {tot }}$ values (Fig. $6 \mathrm{~d}$ ), whereas $\sigma_{\mathrm{sp}, 550}$ values (Fig. 6e) are in between the western and southern subclasses. This is possibly caused by more frequent or stronger new particle formation events.

\section{Conclusions}

Hygroscopic diameter growth factors of the submicron free tropospheric aerosol at the high alpine site Jungfraujoch (JFJ) were measured during a 13-month period, resulting in more than 60000 HTDMA scans from the dry sizes $D_{0}=35,50$, $75,110,165$, and $265 \mathrm{~nm}$. Annual mean hygroscopic growth factors were found to increase with increasing particle diameters. However, this size dependence can largely be attributed to the Kelvin effect because corresponding $\kappa$ values are nearly independent of size. Therefore the size dependence of chemical composition in the submicron size range can also be expected to be small. No clear seasonal pattern beyond natural variability was observed for the hygroscopic growth factors. Consequently a constant and sizeindependent $\kappa$ value of $\sim 0.24$ is a good approximation in any model that needs a simple description of the Aitken and 

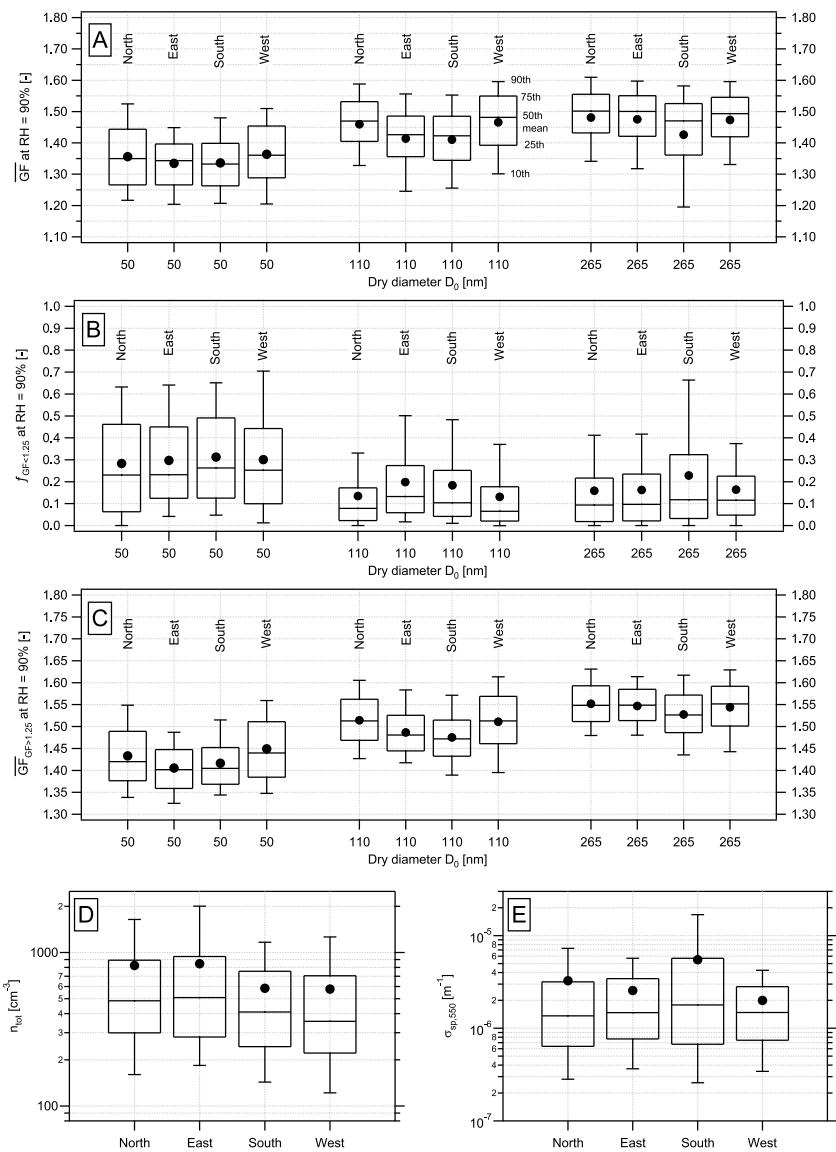

Fig. 6. Percentiles and mean values for advective weather situations clustered by the synoptic scale motions north, east, south, and west at $500 \mathrm{hPa}$ for (A) the mean growth factor $(\overline{\mathrm{GF}})$ at $\mathrm{RH}=90 \%$ for $D_{0}=50,110$, and $265 \mathrm{~nm},(\mathbf{B})$ the number fraction of less hygroscopic particles with $\mathrm{GF}<1.25, f_{\mathrm{GF}<1.25}$, (C) the mean $\mathrm{GF}$ of the more hygroscopic particles with $\mathrm{GF}>1.25, \overline{\mathrm{GF}}_{\mathrm{GF}}>1.25$, (D) the total number concentration, and (E) the scattering coefficient at the wavelength $\lambda=550 \mathrm{~nm}$. Box plots with whiskers show 10th, 25th, 50th, 75th, and 90th percentiles; dots represent mean values.

accumulation mode aerosol at the JFJ site. This value falls within the range of $\kappa$ recommended in a previous study for continental aerosols (Andreae and Rosenfeld, 2008).

The JFJ is also frequently influenced by Saharan dust events (SDE). A comparison of hygroscopic behavior during SDEs shows that the number fraction of mineral dust particles remains negligibly small at $D_{0}<265 \mathrm{~nm}$, even during typical strong SDEs.

A detailed analysis of diurnal patterns was done for different weather classes in order to determine the potential influence from injections of PBL air. During the warmer months a distinct maximum of aerosol loadings in the early afternoon was observed for the convective anticyclonic weather class, and to a lesser extent also for the convective indifferent weather class. Aerosol hygroscopicity decreased concurrently with the increase of aerosol loadings. No distinct diur- nal patterns were observed for the other seasons and weather classes. A comparison of aerosol hygroscopicity during FT conditions with the complete data set revealed that the effect of PBL influence disappears in the annual mean hygroscopicity data.

Aerosol hygroscopicity was found to be virtually independent of synoptic wind direction during advective weather situations, covering more than one third of total measurement time, i.e. when horizontal motion of the atmosphere dominates over thermally driven convection. This is, along with the above results, a strong indication that the hygroscopic behavior of the aerosol observed at the JFJ can be considered to be representative of the lower free troposphere on at least a regional if not continental scale.

The aerosol hygroscopicity data obtained in this study are useful for several other purposes. Jurányi et al. (2010a) showed in a composition-hygroscopicity-CCN closure study for the JFJ aerosol, that HTDMA data are suitable for predictions of $\mathrm{CCN}$ number concentrations from particle number size distribution data if the chemical composition is unknown. This data set can also be used to quantify the influence of ambient RH on light scattering by aerosol particles, which is routinely measured at the JFJ site at dry RH as shown by Fierz-Schmidhauser et al. (2010a). The latter paper also describes the special treatment of SDEs.

\section{Appendix A}

\section{Short-term variability of $\overline{\mathrm{GF}}$}

Here we report detailed statistics of the observed variability of aerosol hygroscopicity as some atmospheric processes may be sensitive to the short-term variability of aerosol hygroscopicity. Fig. A1 shows the mean values as well as the 10th, 25th, 50th (median), 75th and 90th percentiles of individual $\overline{\mathrm{GF}}$ measurements (6 min values) for each month and all investigated dry sizes. Observed $\overline{\mathrm{GF}}$ values are symmetrically distributed about their mean value for the most part, with only a small asymmetry in the 10th and 90th percentiles at the larger dry sizes. The magnitude of the variability is largely independent of season and dry size. The difference between the 25th and 75th percentile, highlighted with the colored shadings in Fig. A1, is always smaller than $\Delta \mathrm{GF}=0.22$ and on average between $\Delta \mathrm{GF}=0.11$ and 0.15 for the different dry sizes. This means that within a month $50 \%$ of all individual $\overline{\mathrm{GF}}$ measured at a certain dry diameter fall into a narrow band with a width of $\Delta \mathrm{GF} \approx 0.15$ around the mean value. The 90th percentile is smaller than 1.60 and the 10th percentile is larger than 1.20 in almost all cases. The true variability of aerosol hygroscopicity may even be slightly smaller than reported in Fig. A1 as the measurements include additional variability due to e.g. limited number of particle counts at low aerosol concentrations. However, this effect should be small as shown by Gysel et al. (2009). 

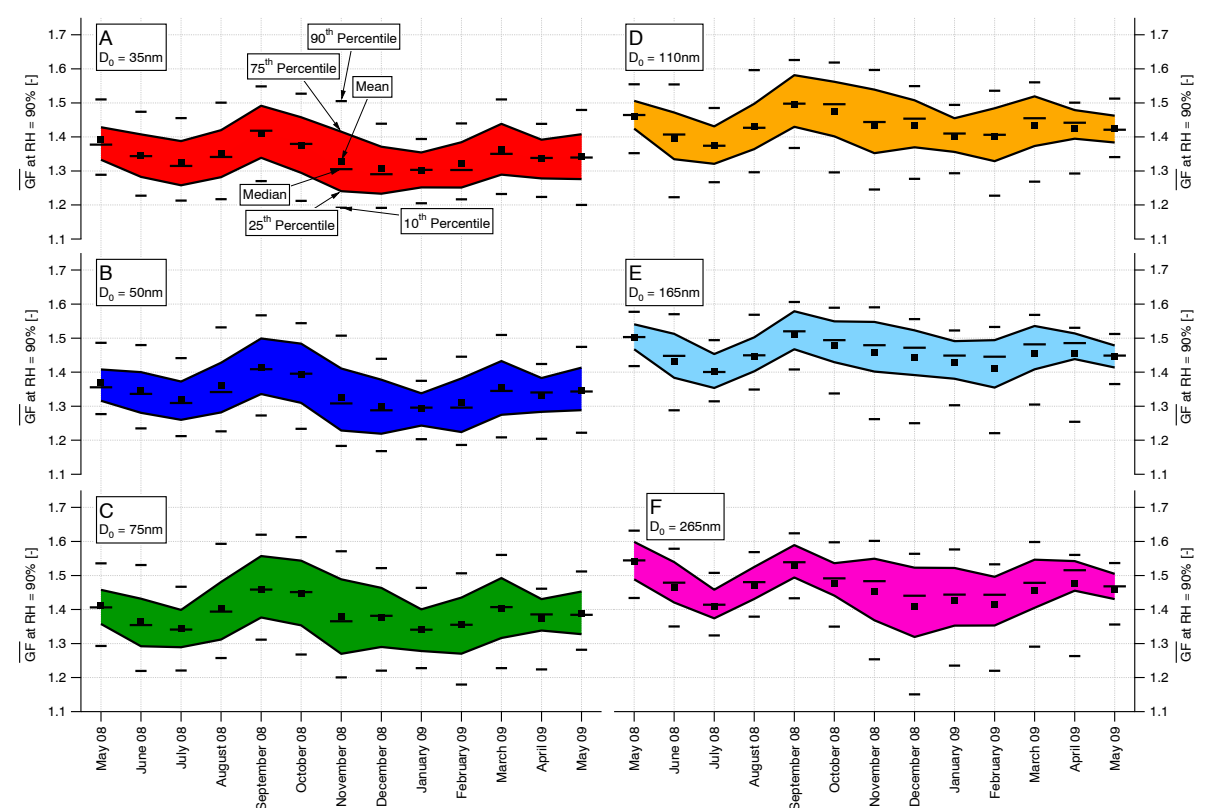

Fig. A1. Monthly statistics of the variability of the mean hygroscopic growth factor $(\overline{\mathrm{GF}})$ at $90 \%$ RH. The 10th, 25th, 50th (median), 75th, and 90th percentiles as well as the mean value of $\overline{\mathrm{GF}}$ are shown in panels A-F for $D_{0}=35,50,75,110,165$, and $265 \mathrm{~nm}$. The GF range spanned by the 1 st and 3rd quartiles is highlighted with a shading.

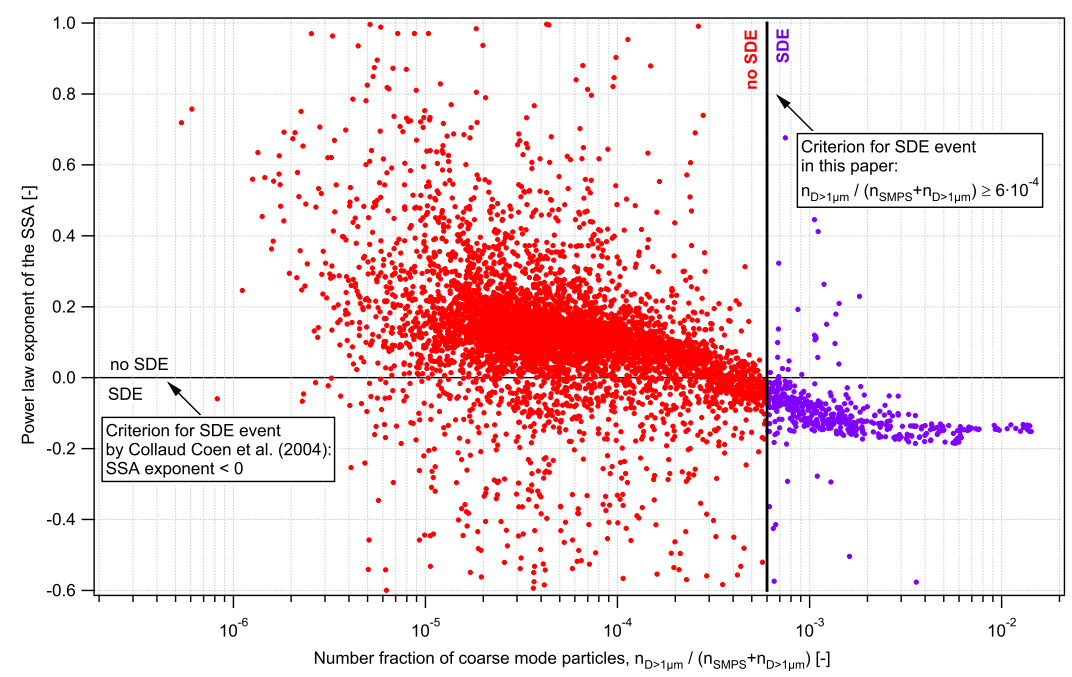

Fig. B1. 4-h average values of the power law exponent of the single scattering albedo versus the number fraction of coarse mode particles.

A rough feeling for the variability of chemical composition can be obtained by simply assuming two component particles consisting of inorganic (ammonium sulfate) and organic material with $\kappa$ values of $\sim 0.49$ (Topping et al., 2005) and $\sim 0.10$ (Gysel et al., 2007), respectively, at $\mathrm{RH}=90 \%$. The mean values of the monthly 10th, 25th, 50th, 75th and 90th percentiles of $\overline{\mathrm{GF}}$ at $D_{0}=110 \mathrm{~nm}$ are $1.23,1.37,1.44,1.50$ and 1.55 , respectively, which corresponds to particles consisting approximately $12 \%, 26 \%, 38 \%, 51 \%$, and $62 \%$ by volume of inorganic material according to this simple model.

\section{Appendix B}

\section{Determination of Saharan dust events}

Dry measurements of the light scattering coefficient and the light absorption coefficient were used to calculate the wavelength dependence of the single scattering albedo (SSA, defined as the fraction of total light extinction caused by scattering). The latter can be used as a criterion for Saharan dust events (SDE), since the wavelength dependence of the 

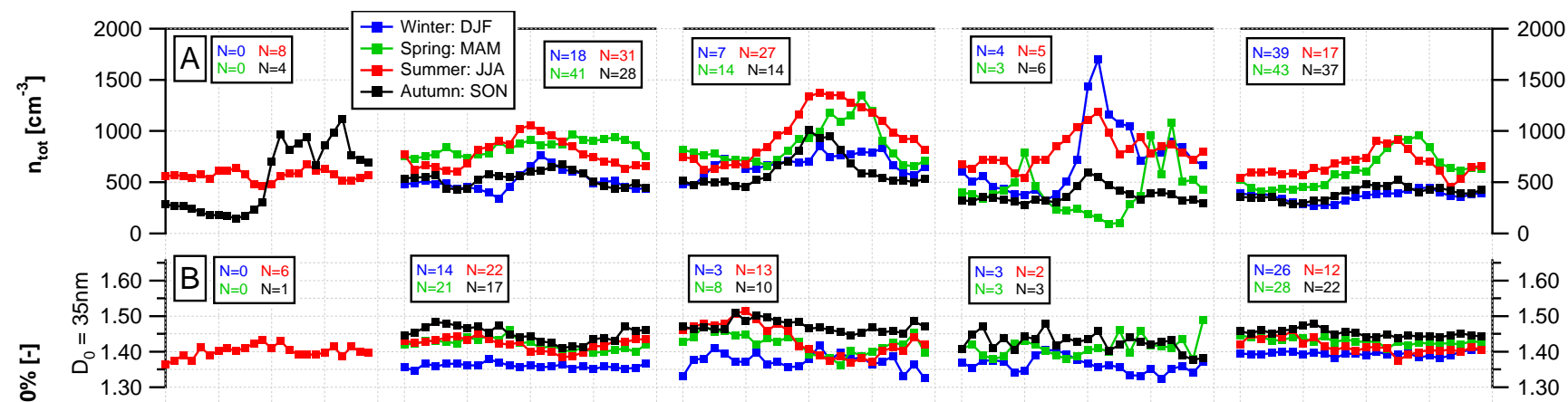

II $\quad$ I $1.60 \exists \mathrm{C}$

峞

至 $1.50-\mathrm{D}$

"O. 1.40 fromensh
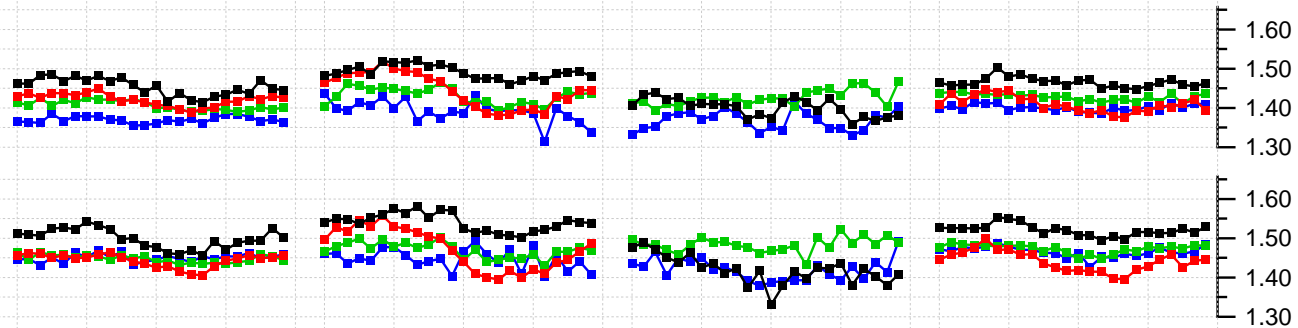

E $1.60-E$

든 1.50

I 1.40 -
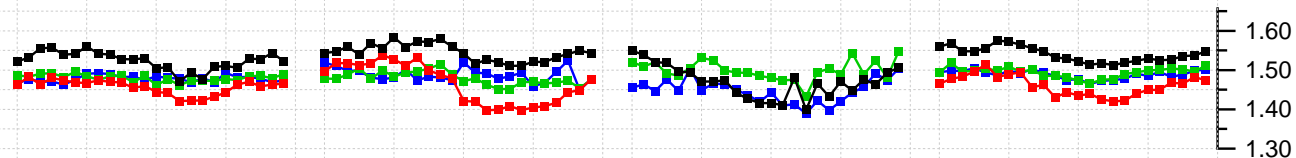

$1.607 \mathrm{~F}$

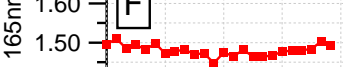

$1.40-$
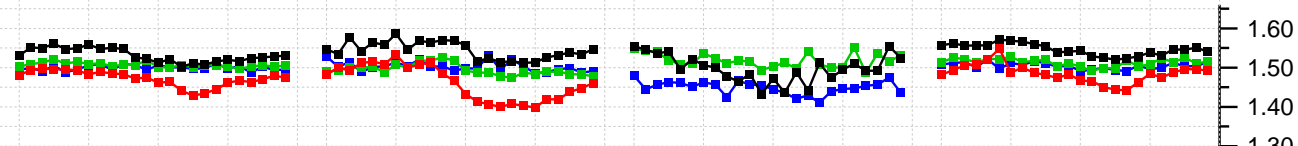
$1.60-\mathrm{G}$

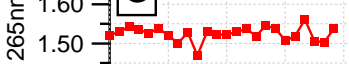 "1.40
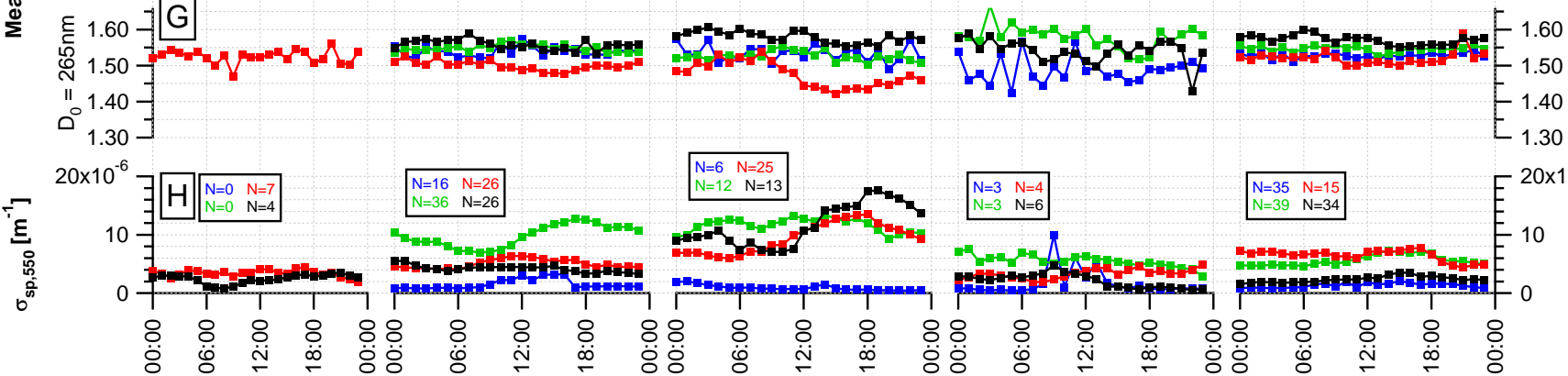

convective cyclon
(lifting)

(small scale circ.)

(subsidence)

mixed (M)

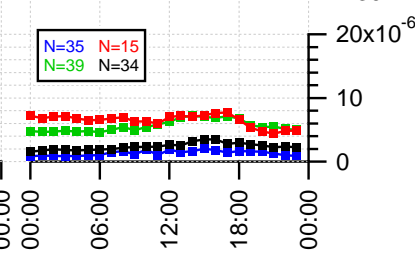

advective (Ax)

(all directions)

Fig. C1. Similar to Fig. 4, except that $\overline{\mathrm{GF}}_{\mathrm{GF}}>1.25$ is shown instead of $\overline{\mathrm{GF}}$ (panels B-G).

SSA in the presence of substantial amounts of mineral dust is inverse compared to non-SDE, so that the power law exponent of the SSA becomes negative (Collaud Coen et al., 2004). Not all parameters to calculate the power law exponent of the SSA were available for the full 13-month period, therefore we use the number fraction of coarse mode particles, $n_{D>1 \mu \mathrm{m}} /\left(n_{\mathrm{SMPS}}+n_{D>1 \mu \mathrm{m}}\right)$ as an alternative indicator of SDE. A scatter plot of the two SDE criteria is shown in Fig. B1 for all times when both of them were simultaneously available. The number fraction of coarse mode particles increases with decreasing power law exponent of the SSA, i.e. with increasing strength of the SDEs. We chose a conserva- tive lower limit of the coarse mode fraction (see Eq. 3) for our SDE criterion such that only strong SDE, when also the SSA-criterion would indicate an SDE, are included (purple markers in Fig. B1).

\section{Appendix C}

Diurnal cycles of hygroscopicity parameters

Analysis of diurnal cycles of $\overline{\mathrm{GF}}_{\mathrm{GF}>1.25}$ (Fig. C1) and $f_{\mathrm{GF}<1.25}$ (Fig. C2) for different weather classes and seasons 

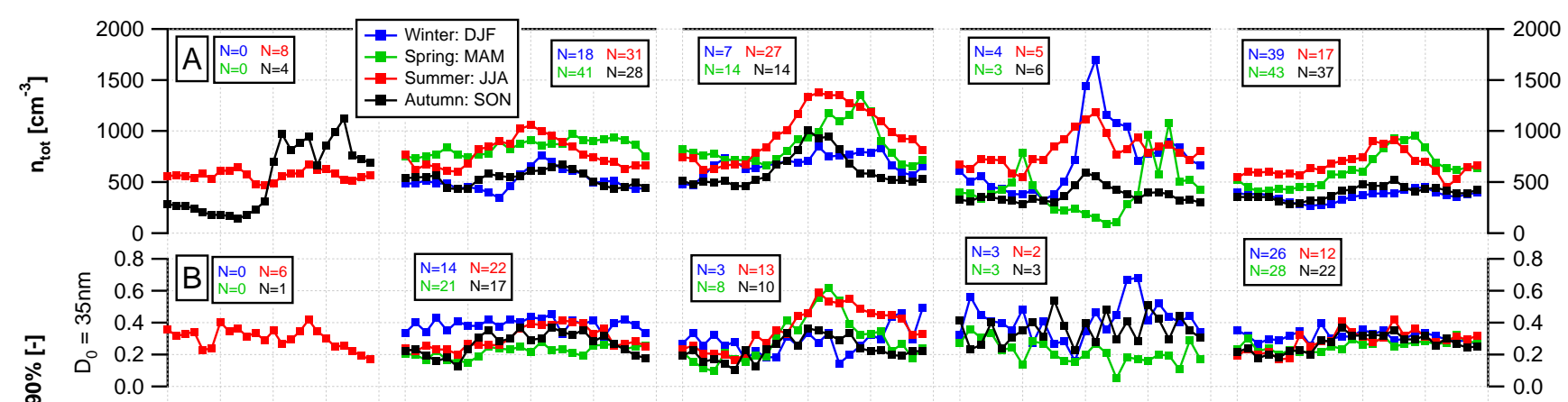

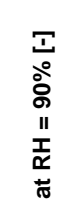

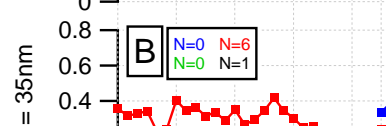

0.2

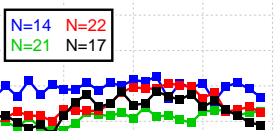

\begin{tabular}{ll}
$\mathrm{N}=3$ & $\mathrm{~N}=13$ \\
$\mathrm{~N}=8$ & $\mathrm{~N}=10$ \\
\hline
\end{tabular}

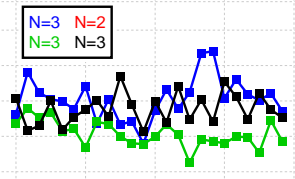

waphoser $\left[\begin{array}{l}0.8 \\ 0.6 \\ 0.4 \\ 0.2 \\ 0.0\end{array}\right.$$$
0.8-\mathrm{C}
$$
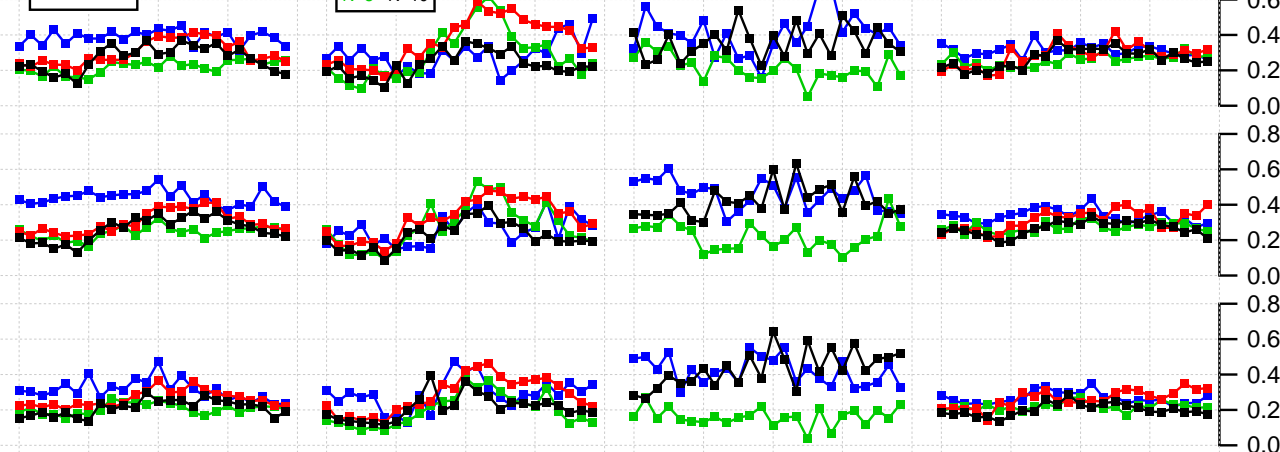

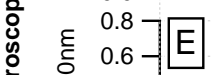

0.2 - 0.0 mand

$\varepsilon^{0.8}-F$

mombether
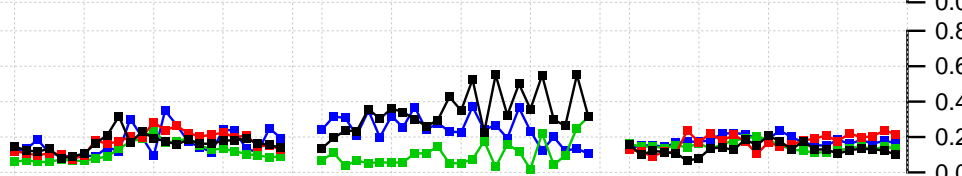

0.6

"O $0.2-1$

- 0.0 M.M.Mr

mathest
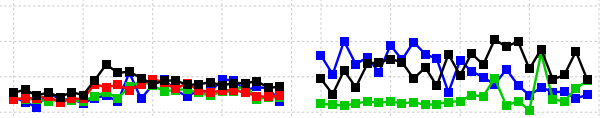

mophymats: -0.2

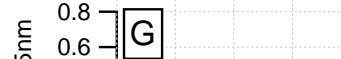

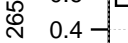

II $0.2-\mathrm{M} M \mathrm{M}$
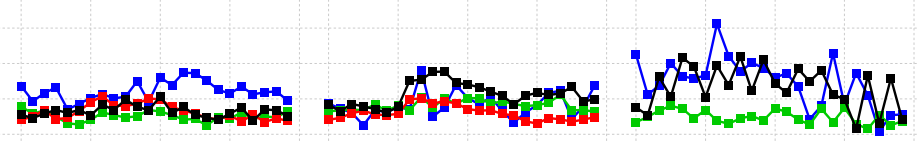

thaphatertap -0.2
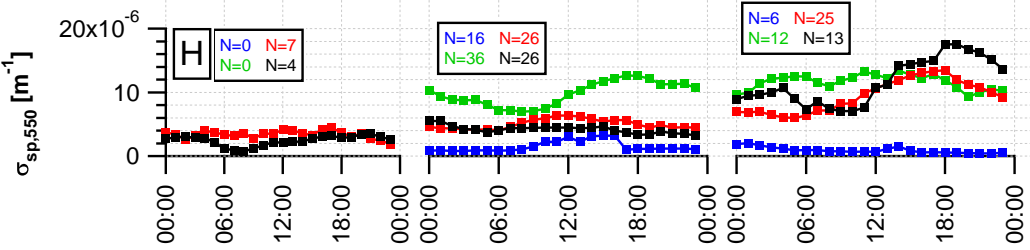

convective cyclo (lifting)

(small scale circ.)

(subsidence)

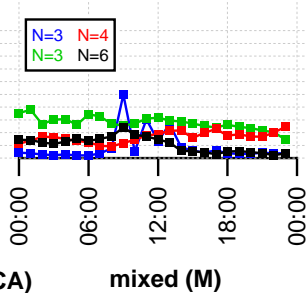

mixed (M)

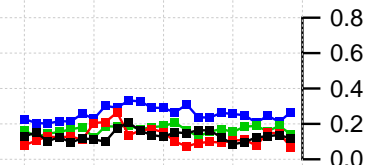

Fig. C2. Similar to Fig. 4, except that $f_{\mathrm{GF}<1.25}$ is shown instead of $\overline{\mathrm{GF}}$ (panels B-G).

was done in exactly the same way as for $\overline{\mathrm{GF}}$ (Sect. 3.1 and Fig. 5) in order to provide complementary information on the reason for diurnal patterns of $\overline{\mathrm{GF}}$. Note, $n_{\text {tot }}$ (panel $\mathrm{A}$ in Figs. $\mathrm{C} 1$ and $\mathrm{C} 2$ ) and $\sigma_{\mathrm{sp}, 550}$ (panel $\mathrm{H}$ in Figs. $\mathrm{C} 1$ and $\mathrm{C} 2$ ) are identical to those shown in Fig. 5. 
Acknowledgements. This work was supported by MeteoSwiss in the framework of the Global Atmosphere Watch program, the Swiss National Science Foundation, and the EU projects EUSAAR and EUCAARI. We thank the International Foundation High Alpine Research Station Jungfraujoch and Gornergrat (HFSJG), who made it possible for us to carry out our experiments at the High Alpine Research Station Jungfraujoch, and we thank the staff at the research station Jungfraujoch: Martin and Joan Fischer, Felix and Susanne Seiler. Further we thank Martine Collaud Coen for helpful discussions about the Alpine Weather Statistics.

Edited by: A. Wiedensohler

\section{References}

Andreae, M. O. and Rosenfeld, D.: Aerosol-cloud-precipitation interactions. Part 1. The nature and sources of cloud-active aerosols, Earth Sci. Rev., 89, 13-41, 2008.

Baltensperger, U., Gäggeler, H. W., Jost, D. T., Lugauer, M., Schwikowski, M., Weingartner, E., and Seibert, P.: Aerosol climatology at the high-alpine site Jungfraujoch, Switzerland, J. Geophys. Res., 102, 19707-19715, doi:10.1029/97JD00928, 1997.

Collaud Coen, M., Weingartner, E., Schaub, D., Hueglin, C., Corrigan, C., Henning, S., Schwikowski, M., and Baltensperger, U.: Saharan dust events at the Jungfraujoch: detection by wavelength dependence of the single scattering albedo and first climatology analysis, Atmos. Chem. Phys., 4, 2465-2480, doi:10.5194/acp4-2465-2004, 2004.

Collaud Coen, M., Weingartner, E., Nyeki, S., Cozic, J., Henning, S., Verheggen, B., Gehrig, R., and Baltensperger, U.: Long-term trend analysis of aerosol variables at the high-alpine site Jungfraujoch, J. Geophys. Res., 112, D13213, doi:10.1029/ 2006JD007995, 2007.

Collaud Coen, M., Weingartner, E., Nessler, R., Nyeki, S., Cozic, J., Henning, S., Verheggen, B., and Baltensperger, U.: Seasonal and diurnal cycles of aerosol optical parameters at the Jungfraujoch depending on synoptic weather condition., in preparation, 2010.

Cozic, J., Verheggen, B., Weingartner, E., Crosier, J., Bower, K. N., Flynn, M., Coe, H., Henning, S., Steinbacher, M., Henne, S., Collaud Coen, M., Petzold, A., and Baltensperger, U.: Chemical composition of free tropospheric aerosol for PM1 and coarse mode at the high alpine site Jungfraujoch, Atmos. Chem. Phys., 8, 407-423, doi:10.5194/acp-8-407-2008, 2008.

Duplissy, J., Gysel, M., Sjogren, S., Meyer, N., Good, N., Kammermann, L., Michaud, V., Weigel, R., Martins dos Santos, S., Gruening, C., Villani, P., Laj, P., Sellegri, K., Metzger, A., McFiggans, G. B., Wehrle, G., Richter, R., Dommen, J., Ristovski, Z., Baltensperger, U., and Weingartner, E.: Intercomparison study of six HTDMAs: results and recommendations, Atmos. Meas. Tech., 2, 363-378, doi:10.5194/amt-2-363-2009, 2009.

Fierz-Schmidhauser, R., Zieger, P., Gysel, M., Kammermann, L., DeCarlo, P. F., Baltensperger, U., and Weingartner, E.: Measured and predicted aerosol light scattering enhancement factors at the high alpine site Jungfraujoch, Atmos. Chem. Phys., 10, 2319 2333, doi:10.5194/acp-10-2319-2010, 2010a.

Fierz-Schmidhauser, R., Zieger, P., Wehrle, G., Jefferson, A., Ogren, J. A., Baltensperger, U., and Weingartner, E.: Measurement of relative humidity dependent light scattering of aerosols, Atmos. Meas. Tech., 3, 39-50, doi:10.5194/amt-3-392010, 2010b.

Gysel, M., Weingartner, E., and Baltensperger, U.: Hygroscopicity of aerosol particles at low temperatures. 2. Theoretical and experimental hygroscopic properties of laboratory generated aerosols, Environ. Sci. Technol., 36, 63-68, 2002.

Gysel, M., Crosier, J., Topping, D. O., Whitehead, J. D., Bower, K. N., Cubison, M. J., Williams, P. I., Flynn, M. J., McFiggans, G. B., and Coe, H.: Closure study between chemical composition and hygroscopic growth of aerosol particles during TORCH2, Atmos. Chem. Phys., 7, 6131-6144, 2007, http://www.atmos-chem-phys.net/7/6131/2007/.

Gysel, M., McFiggans, G. B., and Coe, H.: Inversion of tandem differential mobility analyser (TDMA) measurements, J. Aerosol. Sci., 40, 134-151, 2009.

Hegg, D. A., Covert, D. S., Jonsson, H., and Covert, P. A.: An instrument for measuring size-resolved aerosol hygroscopicity at both sub- and super-micron sizes, Aerosol Sci. Tech., 41, 873883, 2007.

Henning, S., Weingartner, E., Schmidt, S., Wendisch, M., Gäggeler, H. W., and Baltensperger, U.: Size-dependent aerosol activation at the high-alpine site Jungfraujoch (3580 m asl), Tellus B, 54, 82-95, 2002.

IPCC: Climate Change 2007: The Physical Science Basis. Contribution of Working Group I to the Fourth Assessment Report of the Intergovernmental Panel on Climate Change, Cambridge University Press, Cambridge, UK and New York, NY, USA, 2007.

Jurányi, Z., Gysel, M., Weingartner, E., DeCarlo, P. F., Kammermann, L., and Baltensperger, U.: Measured and modelled cloud condensation nuclei concentration at the high alpine site Jungfraujoch, Atmos. Chem. Phys., 10, 7891-7906, doi:10.5194/acp-10-7891-2010, 2010a.

Jurányi, Z., Gysel, M., Weingartner, E., Bukowiecki, N., Kammermann, L., and Baltensperger, U.: 17-month climatology of the cloud condensation nuclei number concentration at the high alpine site Jungfraujoch, submitted, J. Geophys. Res., 2010b.

Köhler, H.: The nucleus in and the growth of hygroscopic droplets, T. Faraday Soc., 32, 1152-1161, 1936.

Liu, B. Y. H., Pui, D. Y. H., Whitby, K. T., Kittelson, D. B., Kousaka, Y., and McKenzie, R. L.: Aerosol mobility chromatograph - new detector for sulfuric-acid aerosols, Atmos. Environ., 12, 99-104, 1978.

Lohmann, U. and Feichter, J.: Global indirect aerosol effects: a review, Atmos. Chem. Phys., 5, 715-737, doi:10.5194/acp-5-7152005, 2005.

Lugauer, M., Baltensperger, U., Furger, M., Gäggeler, H. W., Jost, D. T., Schwikowski, M., and Wanner, H.: Aerosol transport to the high Alpine sites Jungfraujoch (3454 m asl) and Colle Gnifetti (4452 m asl), Tellus B, 50, 76-92, 1998.

McFiggans, G., Artaxo, P., Baltensperger, U., Coe, H., Facchini, M. C., Feingold, G., Fuzzi, S., Gysel, M., Laaksonen, A., Lohmann, U., Mentel, T. F., Murphy, D. M., O’Dowd, C. D., Snider, J. R., and Weingartner, E.: The effect of physical and chemical aerosol properties on warm cloud droplet activation, Atmos. Chem. Phys., 6, 2593-2649, doi:10.5194/acp-6-2593-2006, 2006.

Nessler, R., Bukowiecki, N., Henning, S., Weingartner, E., and Baltensperger, U: Simultaneous dry and ambient measurements of 
aerosol size distribution at the Jungfraujoch, Tellus B, 55, 808819, doi:10.1034/j.1600-0889.2003.00067.x, 2003.

Nyeki, S., Baltensperger, U., Colbeck, I., Jost, D. T., Weingartner, E., and Gäggeler, H. W.: The Jungfraujoch high-Alpine research station (3454 m) as a background clean continental site for the measurement of aerosol parameters, J. Geophys. Res., 103, 6097-6107, doi:10.1029/97JD03123, 1998.

Nyeki, S., Kalberer, M., Colbeck, I., De Wekker, S., Furger, M., Gäggeler, H. W., Kossmann, M., Lugauer, M., Steyn, D., Weingartner, E., Wirth, M., and Baltensperger, U.: Convective boundary layer evolution to $4 \mathrm{~km}$ asl over high-alpine terrain: Airborne lidar observations in the Alps, Geophys. Res. Lett., 27, 689-692, doi:10.1029/1999GL010928, 2000.

Petters, M. D. and Kreidenweis, S. M.: A single parameter representation of hygroscopic growth and cloud condensation nucleus activity, Atmos. Chem. Phys., 7, 1961-1971, doi:10.5194/acp-71961-2007, 2007.

Schüepp, M.: Klimatologie der Schweiz, Band III, Witterungsklimatologie, Schweizerische Meteorologische Anstalt, Zürich, Switzerland, 1979.

Sjogren, S., Gysel, M., Weingartner, E., Alfarra, M. R., Duplissy, J., Cozic, J., Crosier, J., Coe, H., and Baltensperger, U.: Hygroscopicity of the submicrometer aerosol at the high-alpine site Jungfraujoch, $3580 \mathrm{~m}$ a.s.l., Switzerland, Atmos. Chem. Phys., 8, 5715-5729, doi:10.5194/acp-8-5715-2008, 2008.

Swietlicki, E., Zhou, J. C., Covert, D. S., Hameri, K., Busch, B., Vakeva, M., Dusek, U., Berg, O. H., Wiedensohler, A., Aalto, P., Makela, J., Martinsson, B. G., Papaspiropoulos, G., Mentes, B., Frank, G., and Stratmann, F.: Hygroscopic properties of aerosol particles in the northeastern Atlantic during ACE-2, Tellus B, 52, 201-227, 2000.
Swietlicki, E., Hansson, H. C., Hameri, K., Svenningsson, B., Massling, A., McFiggans, G., McMurry, P. H., Petaja, T., Tunved, P., Gysel, M., Topping, D., Weingartner, E., Baltensperger, U., Rissler, J., Wiedensohler, A., and Kulmala, M.: Hygroscopic properties of submicrometer atmospheric aerosol particles measured with H-TDMA instruments in various environments - a review, Tellus B, 60, 432-469, 2008.

Thomson, S. W.: On the equilibrium of vapour at a curved surface of liquid, Philosophical Magazine, 4, 448-452, 1871.

Topping, D. O., McFiggans, G. B., and Coe, H.: A curved multicomponent aerosol hygroscopicity model framework: Part 1 -Inorganic compounds, Atmos. Chem. Phys., 5, 1205-1222, doi:10.5194/acp-5-1205-2005, 2005.

Van Dingenen, R., Putaud, J.-P., Martins-Dos Santos, S., and Raes, F.: Physical aerosol properties and their relation to air mass origin at Monte Cimone (Italy) during the first MINATROC campaign, Atmos. Chem. Phys., 5, 2203-2226, doi:10.5194/acp-52203-2005, 2005.

Wanner, H., Salvisberg, E., Rickli, R., and Schüepp, M.: 50 years of Alpine Weather Statistics (AWS), Meteorol. Z., 7, 99-111, 1998.

Weingartner, E., Nyeki, S., and Baltensperger, U.: Seasonal and diurnal variation of aerosol size distributions $(10<D<750 \mathrm{~nm})$ at a high-alpine site (Jungfraujoch $3580 \mathrm{~m}$ asl), J. Geophys. Res., 104, 26809-26820, doi:10.1029/1999JD900170, 1999.

Weingartner, E., Gysel, M., and Baltensperger, U.: Hygroscopicity of aerosol particles at low temperatures. 1. New low-temperature H-TDMA instrument: Setup and first applications, Environ. Sci Technol., 36, 55-62, 2002. 